\title{
NUEVAS POSIBILIDADES DEL DIBUJO TÉCNICO A TRAVÉS DE UNA INVESTIGACIÓN EDUCATIVA BASADA EN LAS ARTES
}

\section{APROXIMACIÓN A LA MODA SURREALISTA A TRAVÉS DE LAS PERSPECTIVAS IMPOSIBLES DE M.C. ESCHER}

\author{
NEW POSSIBILITIES OF TECHNICAL DRAWING \\ THROUGH EDUCATIONAL RESEARCH BASED ON \\ THE ARTS. APPROACH TO SURREALIST FASHION \\ THROUGH THE IMPOSSIBLE PERSPECTIVES OF M.C. \\ ESCHER
}

\section{Dr. Manuel Pérez-Valero \\ Universidad de Granada (1) https://orcid.org/0000-0001-7410-6375}

\section{Ángela Gómez-Martín}

Escuela Superior de Arte y Diseño de Andalucía (1D https://orcid.org/0000-0002-0821-6688

\section{Resumen}

Este artículo muestra una investigación educativa basada en las artes en la formación del profesorado (2017-2020) realizada para la asignatura "Aprendizaje y Enseñanza del Dibujo Técnico" del Máster en Profesorado de Educación Secundaria Obligatoria y Bachillerato, Formación Profesional y Enseñanza de Idiomas, en la especialidad de Dibujo, Imagen y Artes Plásticas (Universidad de Almería). Los perfiles del alumnado son dispares: arquitectos, ingenieros técnicos, diseñadores gráficos, licenciados en Bellas Artes, licenciados en Historia del Arte, en Publicidad, Moda y Relaciones Públicas, por lo que los procesos son, al mismo tiempo, muy complejos, pero muy enriquecedores, aportando nuevas perspectivas a los enfoques de la enseñanza-aprendizaje del Dibujo Técnico.

Se ha desarrollado una metodología de investigación artística participativa, colaborativa, creativa y experimental en formato de laboratorio con la idea de diseñar programas o, mejor dicho, experiencias, que estimulen el interés del alumnado y la investigación autónoma del mismo.

Se pretende abordar el estudio de la representación gráfica y del espacio mediante nuevas vías que acompañen al dibujo técnico y se vean reflejadas en las inquietudes de los discentes, como puede ser, en este caso en particular, el mundo de la Moda. Pero también es importante saber y entender que esta materia puede conducirnos al mundo del Teatro, el Constructivismo o el Video Mapping.

\section{Palabras clave}

Investigación educativa basada en las artes; dibujo técnico; formación docente; laboratorio experimental; moda. 


\begin{abstract}
This article presents educational research based on arts in teacher's training (2017-2020) carried out for the subject "Learning and Teaching of Technical Drawing" of the Master's Degree in Teaching of Compulsory Secondary Education and High School, Vocational Training and Language Teaching, in the specialty of Drawing, Image and Plastic Arts (University of Almería). The profiles of the students are diverse: architects, technical engineers, graphic designers, graduates in Fine Arts, graduates in History of Art, graduates in Advertising, Fashion and Public Relations. The processes are therefore, at the same time, very complex, although very enriching, bringing new perspectives to the approaches of teaching-learning of Technical Drawing.
\end{abstract}

We have developed a methodology of participative, collaborative, creative and experimental artistic research in a laboratory format with the idea of designing programs, or - to be more precise - experiences that stimulate the interest of the students and their autonomous research.

The aim is to address the study of graphic representation and space through new channels that accompany technical drawing and are reflected in students' concerns, such as, in this particular case, the world of fashion. However, it is also important to know and understand that this subject can lead us to the world of Theatre, Constructivism and even Video Mapping.

\title{
Keywords
}

Arts-based Educational Research, technical drawing, teacher training, experimental laboratory, fashion.

\section{INTRODUCCIÓN}

El modelo educativo para la enseñanza-aprendizaje del Dibujo Técnico está demasiado generalizado y su fuerte carácter tradicional repercute negativamente en el alumnado, al recibir o asistir a clases magistrales que pueden perturbar el normal desarrollo de procesos didácticos sin más motivación que la información o el conocimiento. Actualmente, es un factor importante, por lo tanto, favorecer los grupos de trabajo, los ambientes de experimentación y el intercambio de información, no solo por el desarrollo intelectual del discente sino también por propiciar aspectos intrapersonales en la enseñanza que acrecienten la ampliación de su autoestima y por ello de sus expectativas, como alumnado y como futuro docente de la materia.

Esta investigación parte del análisis y experimentación estética de procesos artísticos vinculados de una forma directa al dibujo técnico. Existe la necesidad de superar este estado adormecido actual que ha afectado a nuestra capacidad innata de entender con los ojos, hay que volver a despertarla y, para ello, se instruirá en evidencias visuales que corrijan malos hábitos, muestren puntos débiles y presenten buenos ejemplos en el acto de dibujar (Arnheim, 2005). Dejar de pensar demasiado en el dibujo para acabar con las inseguridades.

Es sabido que la materia de Dibujo Técnico, a menudo, supone en el alumnado momentos de desmotivación, seguramente debido a la falta de vinculación con las propias inquietudes del discente y con el mundo contemporáneo que le ha tocado habitar y conocer. Para ello, se debe entender el dibujo técnico como una herramienta de investigación y especulación que permitirá abrir nuevos campos de conocimiento más representativos de la sociedad contemporánea. Y, sobre todo, como esto afecta al adolescente de Secundaria con ganas de descubrir -se usa este verbo, descubrir, y no aprender porque el efecto sorpresa siempre será una herramienta fundamental en el campo de la educación-.

Como parte fundamental dentro de la investigación se ha presentado al alumnado, futuro profesorado, conocimientos básicos de los métodos y herramientas de representación utilizados en el Arte, así como principios fundamentales de la representación del espacio. Durante el aprendizaje del Dibujo Técnico, como indica Lino Cabezas (2003, p. 303), se han de complementar dos tipos de perspectivas: la matemática, que se argumenta desde la geometría; y la perspectiva intuitiva, que se realiza a ojo, sin la ayuda de una metodología geométrica. Se han estudiado aquellos diseños que ya existen en la naturaleza y que nos llevan de una forma directa al dibujo geométrico, los diseños de repetición y las ilusiones ópticas. Para ello se mostrará al alumnado el estilo gráfico del 
New Age, Op-Art y Art Decó, y artistas como Victor Vasarely, Andy Warhol y Bridgent Riley, al tener una clara relación con el mundo natural y la producción humana.

A través de la imagen visual, el arte contemporáneo y las características más importantes de la espacialidad, se estudiaron las principales generalidades y clasificaciones de los tipos de representación en el dibujo técnico (planos acotados, sistema diédrico, sistema axonométrico, perspectiva cónica). Así, esta metodología permitirá al profesorado en formación manejar nuevos enfoques de enseñanza y aprendizaje, nuevos caminos de investigación que influyan en su metodología docente; y ampliar y refinar su percepción espacial con ejercicios creativos y atractivos que fomenten el dibujo técnico como una herramienta de investigación que sirva de punto de partida para adentrarse en otras disciplinas. Se trata de estimular el deseo como estrategia motivadora y, por lo tanto, detonante de nuevos modos de aprender, donde la emoción y lo cognitivo propicien nuevos proyectos pedagógico-creadores (Caeiro, 2018).

No hay que olvidar que, aunque la perspectiva es imprescindible para representar fielmente el espacio y es uno de los métodos que más se aproxima a la realidad, también es una adaptación, una invención, pues la exactitud matemática que posee el dibujo técnico no se corresponde con las manifestaciones del modelo real. Por ello es fundamental que el alumnado comprenda el motor de la investigación que nos ocupa, conocer hacia dónde le puede llevar el dibujo técnico, entender la relación del espacio con los elementos que le rodean y propiciar estrategias de experimentación que fortalezcan esa conexión Dibujo Técnico - Educación - Arte Contemporáneo - Moda.

\section{DIBUJO TÉCNICO Y NUEVAS POSIBILIDADES DE INVESTIGACIÓN ARTÍSTICA EN LA FORMACIÓN INICIAL DEL PROFESORADO}

El Dibujo Técnico es una disciplina dentro del mundo artístico que nos permite conocer el espacio, habitarlo, deshabitarlo y relacionarlo con otros elementos. Es un proceso similar al del volumen que ocupamos o dejamos libre al ponernos un traje o un sombrero. La prenda de vestir se transforma entonces en un entorno arquitectónico que invita a reflexionar y a poner en práctica y relación el arte de la arquitectura con el resto de nuestros sentidos (Pallasmaa, 2014), como las creaciones de Leon Battista Alberti o Filippo Brunelleschi, que juegan con las mismas instrucciones que posee el dibujo técnico. Pero una vez conocidas esas instrucciones, al igual que les ocurría a los artistas de vanguardia, es hora de romper con ellas con reflexión y sentido, dejar a un lado la perspectiva natural y encontrar nuevas posibilidades en la imaginación y la fantasía. Para ello, un buen ejemplo es conocer, después de haber estudiado las diferentes formas de representación espacial, los universos de M.C. Escher.

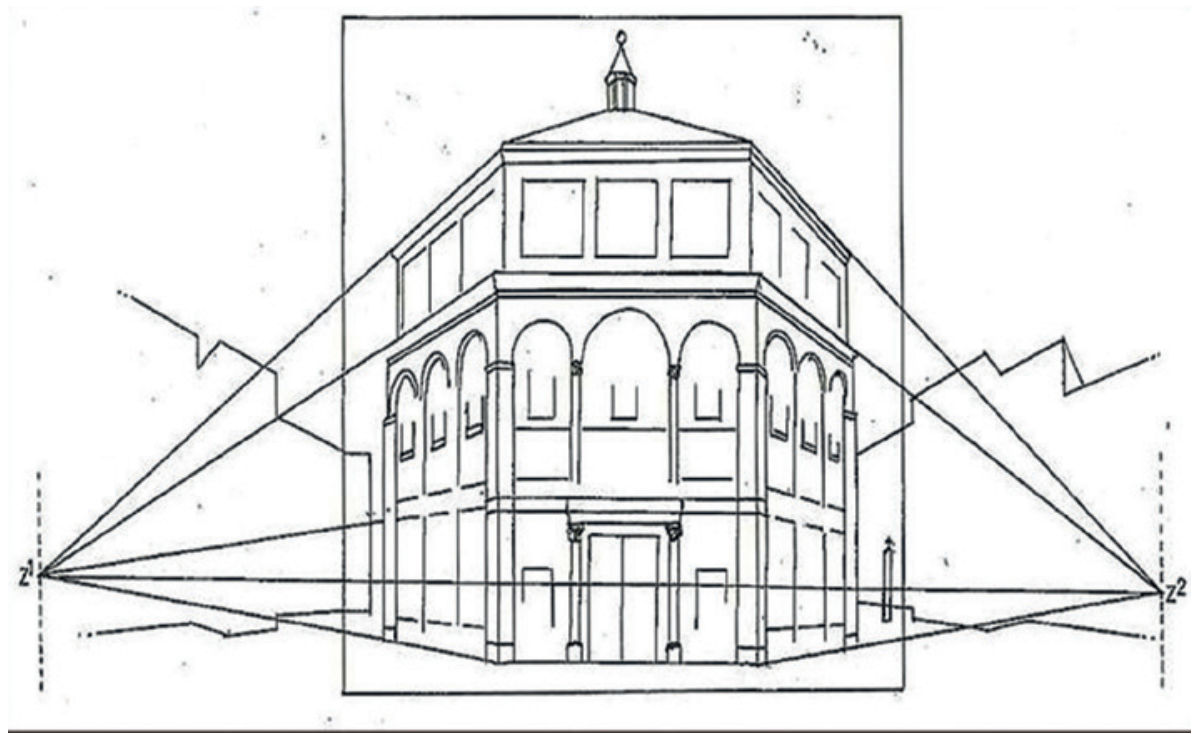

Imagen 1. Estudio de la perspectiva de Brunelleschi, extraído el 18.05.2020 de: https://alexchessani.wordpress.com/renacimiento/ 
Ahora se pondrá énfasis en la relación evidente entre Dibujo Técnico y Moda cuando se hace referencia a procesos de patronaje o composiciones. También es importante conocer la moda a través del dibujo técnico porque esto significa conocer la sociedad contemporánea. La moda es una conciencia colectiva capaz de excluir a aquel individuo que sienta rechazo sobre ella (Squicciarino, 2012). ¿Es que acaso solo el dibujo artístico puede estar dotado de sensibilidad, de reflexión o de compromiso?

La moda o la prenda, al igual que ocurre con las palabras en una frase o con las líneas sobre un papel, puede tener varios significados, usar varios lenguajes de conocimiento plástico para comunicar, muy similar en este sentido al acto pedagógico. En la moda, como ocurre con el habla o con la educación, los significados dependen del contexto que con las circunstancias pueden verse alterados (Lurie, 2002). No se habla, educa 0 diseña en un vacío, sino atendiendo a un espacio y tiempo específicos. El docente siempre debe tener en cuenta lo que está sucediendo fuera del aula, para que los contenidos del currículum puedan adaptarse no solo a las necesidades académicas del alumnado, sino también a sus inquietudes como miembros de la colectividad.

Al igual que el esbozo y la ilustración son métodos indudablemente usados en los procesos de diseño de moda, el dibujo técnico nos ayuda a expresar la idea de un diseño específico desde distintas vistas, a representar su silueta o plantear sus proporciones. Y lo que es más atractivo aún, nos facilita entender el espacio ocupado para después manipularlo. Cuando jugamos y experimentamos con el dibujo técnico, jugamos también con la geometría, con la repetición, con la ilusión óptica. Se experimenta con las distintas dimensiones para comprobar que el espacio y su representación van más allá de la línea, el contorno, la figura y el fondo. Aprendemos para posteriormente desaprender.

Y en este acto de desaprender se podría tomar el rol de un músico de jazz (siempre he apostado por esta metodología), un músico que, a pesar de tener una partitura muy estudiada delante de sus ojos, apuesta por la improvisación, ya que le lleva por diferentes caminos y nuevas posibilidades de creación e investigación. Se potencia así una metodología de aprendizaje heurística para promover que el alumnado adquiera los conocimientos por sí mismo, de forma inductiva. Jerome Bruner (2001) creía en una educación que desarrollara aquella parte intelectual del alumnado que le ayude a favorecer sus habilidades y, por lo tanto, a resolver problemas en su investigación a través del descubrimiento. En consecuencia, el estudiante utiliza su intuición, su imaginación y su creatividad para enfrentarse y superar situaciones de aprendizaje problemáticas (Camargo \& Hederich, 2010).

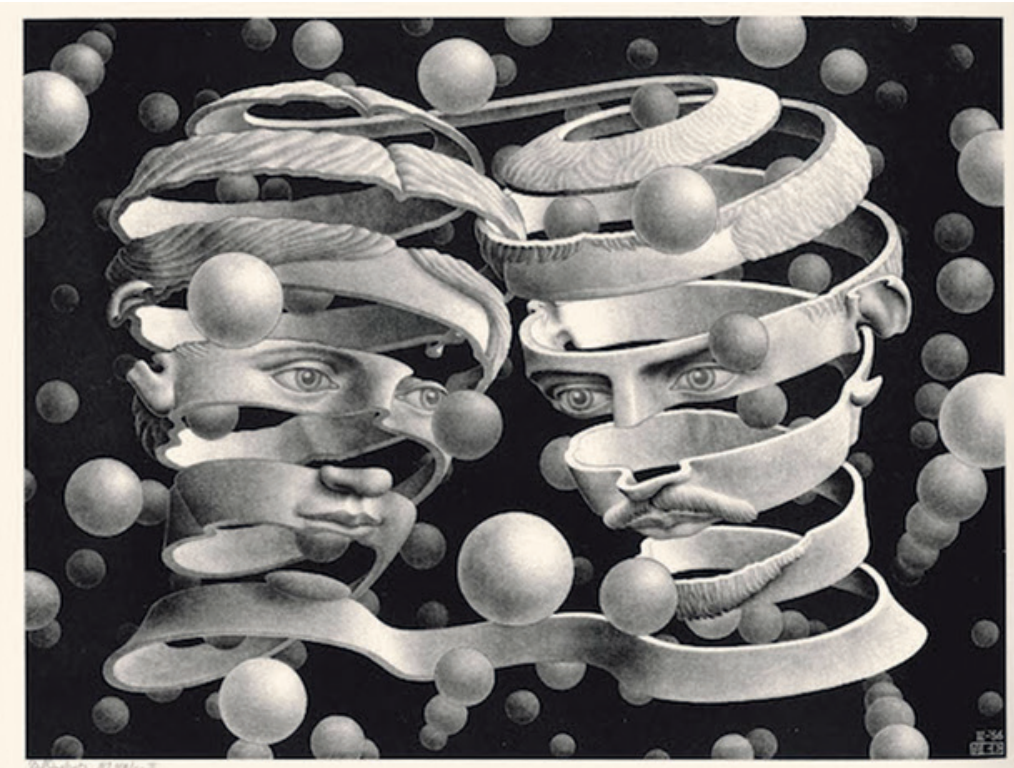

Imagen 2. Escher. Lazo de unión, 1956. Litografía. Recuperado del catálogo artístico M.C. Escher. Infinite Universes (2011). 


\subsection{Del universo surrealista de M. C. Escher a una perspectiva metamorfoseada en sombrero}

A continuación, se muestran de forma breve y precisa aquellos elementos de la investigación que propician esa experimentación con el Dibujo Técnico que pensamos que debe ser fundamental para elaborar la propuesta presentada y el futuro didáctico de la materia.
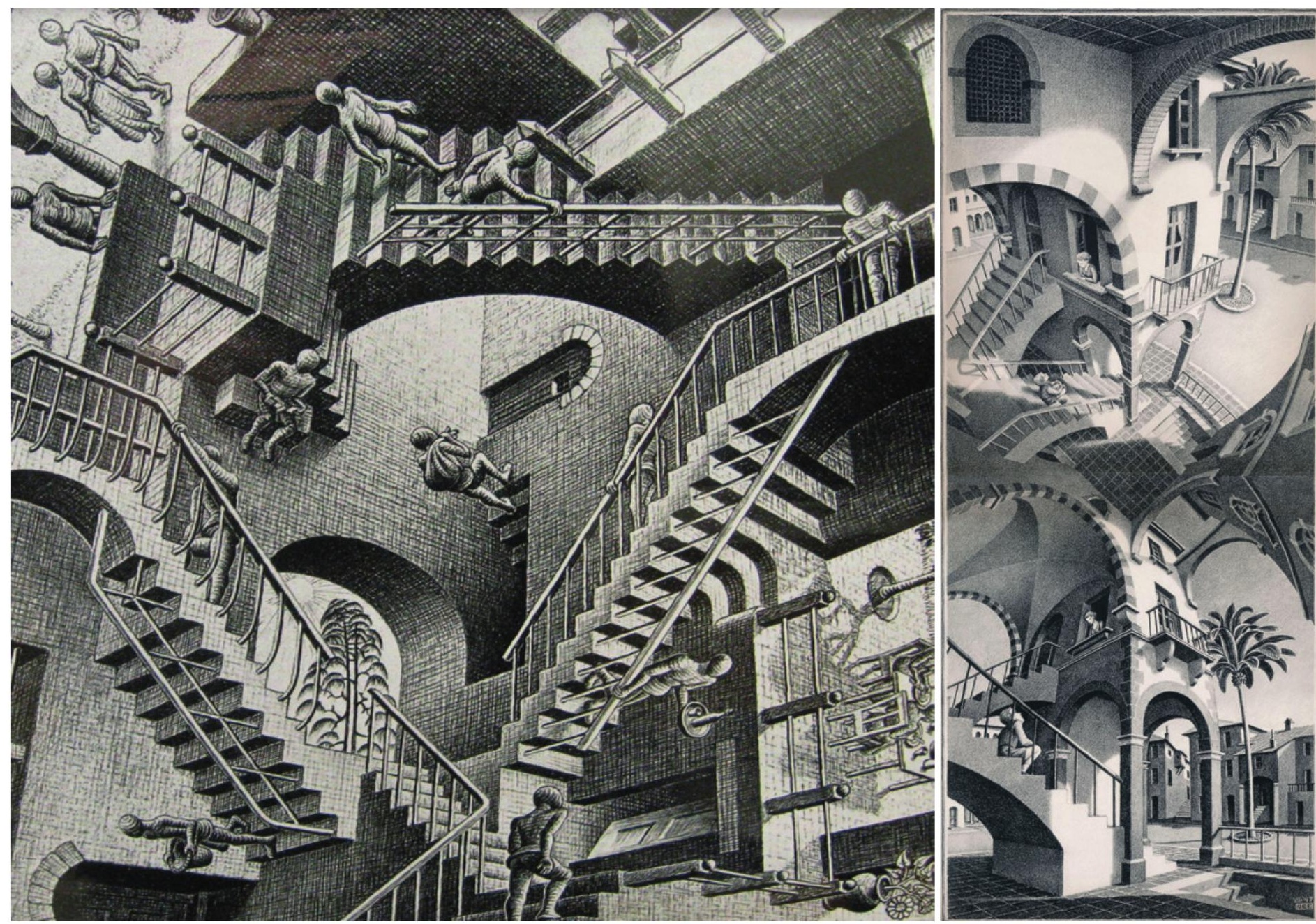

Imágenes 3 y 4. M. C. Escher. Relatividad, 1953. Litografía. Recuperado del catálogo artístico M.C. Escher. Infinite Universes (2011).

\section{C. Escher y la perspectiva infinita}

Comprender e imitar sin caer en la copia, la obra de M.C. Escher es de vital importancia para el desarrollo de la investigación basada en las artes que nos ocupa. Es imprescindible conocer primero la biografía del artista, sus viajes por España, su amor por la Alhambra de Granada, su etapa de representación figurativa, aquellos paisajes del Mediterráneo que mezclaban lo natural y lo artificial, sus metamorfosis geométrico-naturales basadas en la contigüidad de las formas con poemas fundidos en estructuras vegetales, para llegar a esas obras que nos servirán de estudio. Obras en las cuales existe una clara reconstrucción visual de objetos tridimensionales que hacen patente una representación de mundos imposibles e inestables, piezas que dotan de importancia a las formas tridimensionales, a las matemáticas, a la geometrización del plano y, por supuesto, a la arquitectura y la perspectiva. Para esta argumentación artística que marcará los procesos pedagógicos del aula se han tenido en cuenta la exposición de Escher en Granada y el catálogo de dicha exposición M. C. Escher. Infinite Universes (2011). 


\section{Anamorfosis. Magia en la representación}

Con la incorporación del concepto de anamorfosis en la propuesta se muestra un uso particular de las leyes de la perspectiva. Por medio del dibujo se representarán elementos distorsionados que ayudarán a desarrollar nuestra percepción visual. Así, el alumnado asimila la relación transversal entre ciencia y arte para, posteriormente, adaptarla a una producción artística.

La práctica consiste en que el alumnado realice una imagen irreconocible a primera vista para deformarla geométricamente a través de procedimientos perspectivos. La imagen se configura cuando la vemos desde un punto de vista determinado o a través de algún elemento reflectante como un tubo de acero, una lata de conservas o un tubo forrado con papel de aluminio. Existen diferentes tipos de anamorfosis, en este caso en particular se ha trabajado con la anamorfosis cónica y cilíndrica ayudándonos de plantillas que facilitan su elaboración y que se pueden encontrar en el catálogo de la exposición Perspectiva. Ciencia y magia de la representación (2009).
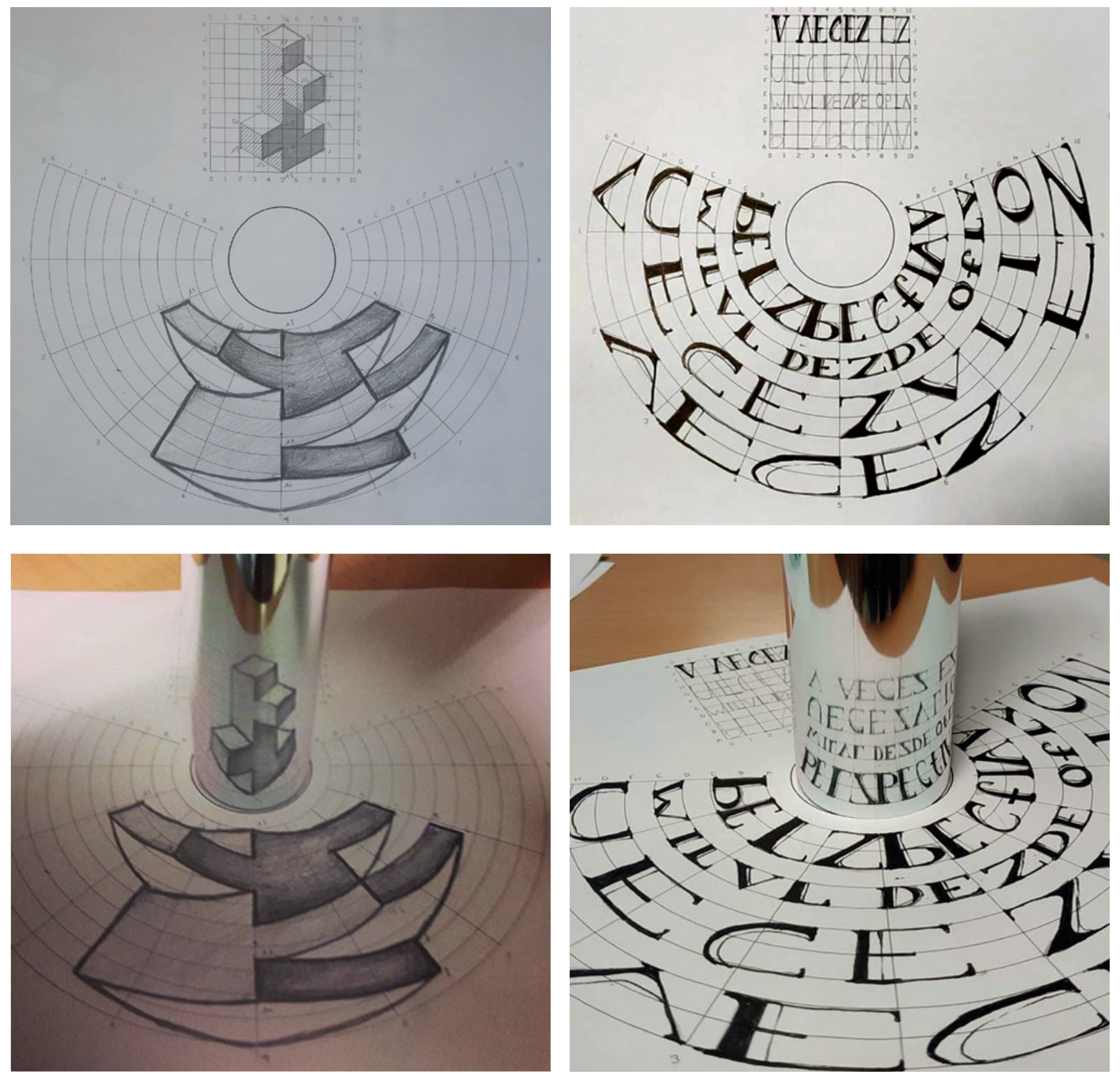

Imágenes 5 y 6. Ejercicios realizados por el alumnado del Máster en profesorado de Educación Secundaria durante el curso académico $2019 / 20$. Imágenes 7 y 8 . Ejercicios realizados por el alumnado del Máster en profesorado de Educación Secundaria durante el curso académico $2019 / 20$. 


\section{El dibujo técnico de moda}

La relación más directa de la Moda con el Dibujo Técnico es sin duda el patronaje, que servirá para expresar las ideas de diseño que después se quieren producir. Se ofrecen al alumnado conocimientos básicos de medidas y patrón para, posteriormente, realizar ejercicios de transformación del patrón tipo, llevando a cabo un método de aprendizaje para cortar por medio de plantillas. La pretensión con esto es olvidar aquellas que "por su complicado mecanismo y antigüedad" dificultan el aprendizaje, con la consiguiente pérdida de tiempo al no ser llevado a la práctica. Se persigue una enseñanza práctica y completa, utilizando un proceso creativo llamado de diseño rápido. El alumnado apreciará cómo puede usar una plantilla de prenda, una vez dibujada, como inspiración para un número infinito de creaciones (Szkutnicka. 2010).

Además del patronaje, hay que destacar una técnica de representación de prendas y accesorios de moda vinculada al proceso de industrialización denominado dibujo técnico de moda, que, como explican Fernández y Martín (2009), consiste en una representación de la prenda a modo de croquis, se dibujan como si estuvieran dispuestas sobre la superficie plana de una mesa y se detallan el frente, espalda y perfil, especificando los tamaños y posición de los diferentes elementos. El dibujo técnico de una prenda se muestra lo más exacto posible en la proporción, sin exageraciones, texturas o sombras, para evitar malentendidos durante el proceso de producción.

El patronaje como doctrina del dibujo técnico, trabaja la proyección en plano de una figura tridimensional, contemplando una serie de requisitos como el movimiento, la comodidad o la sujeción, aunque en esta actividad se opta por encontrar y descubrir nuevas posibilidades en la geometría a través de la experimentación.
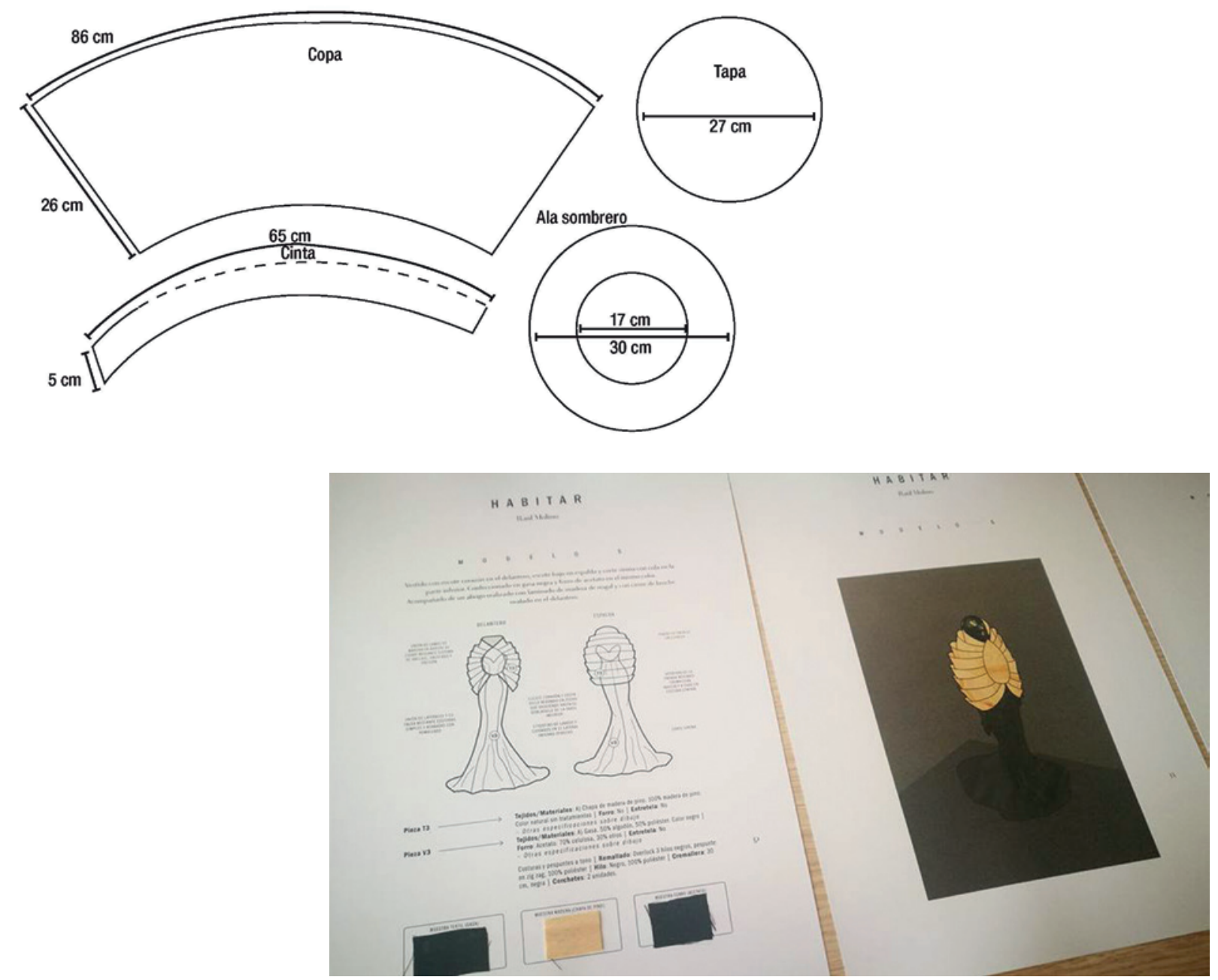


\section{Moda Surrealista. Descosiendo el gusto a través del escándalo}

La investigación del alumnado toma ahora un carácter más personal y así va encontrando su propio lenguaje de expresión. Para ello se le proporcionan referentes como Elsa Schiaparelli, Salvador Dalí, Yohji Yamamoto, Man Ray, Hussein Chalayan y Guda Koster. No debemos pasar por alto que el Surrealismo, en su anhelo por cuestionar absolutamente todo, tuvo muchísima influencia en el arte, y la idea de acercarse a la moda permitió una metamorfosis completa que aún aprovechan diseñadores de la alta costura contemporánea como Moschino o Palomo Spain.

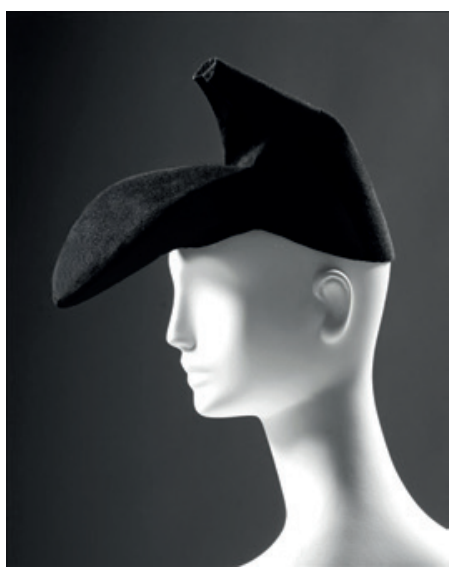

Según Baudot (2003, p. 17), el Surrealismo no ha parado de intervenir en la singularidad de muchas marcas y anuncios de toda una comunicación en relación directa con la moda hasta nuestros días. Debemos tener en cuenta que la moda convierte al portador de la prenda en prescriptor de tendencias, en este caso llevando el surrealismo de la galería a la calle, y del imaginario popular al aula.

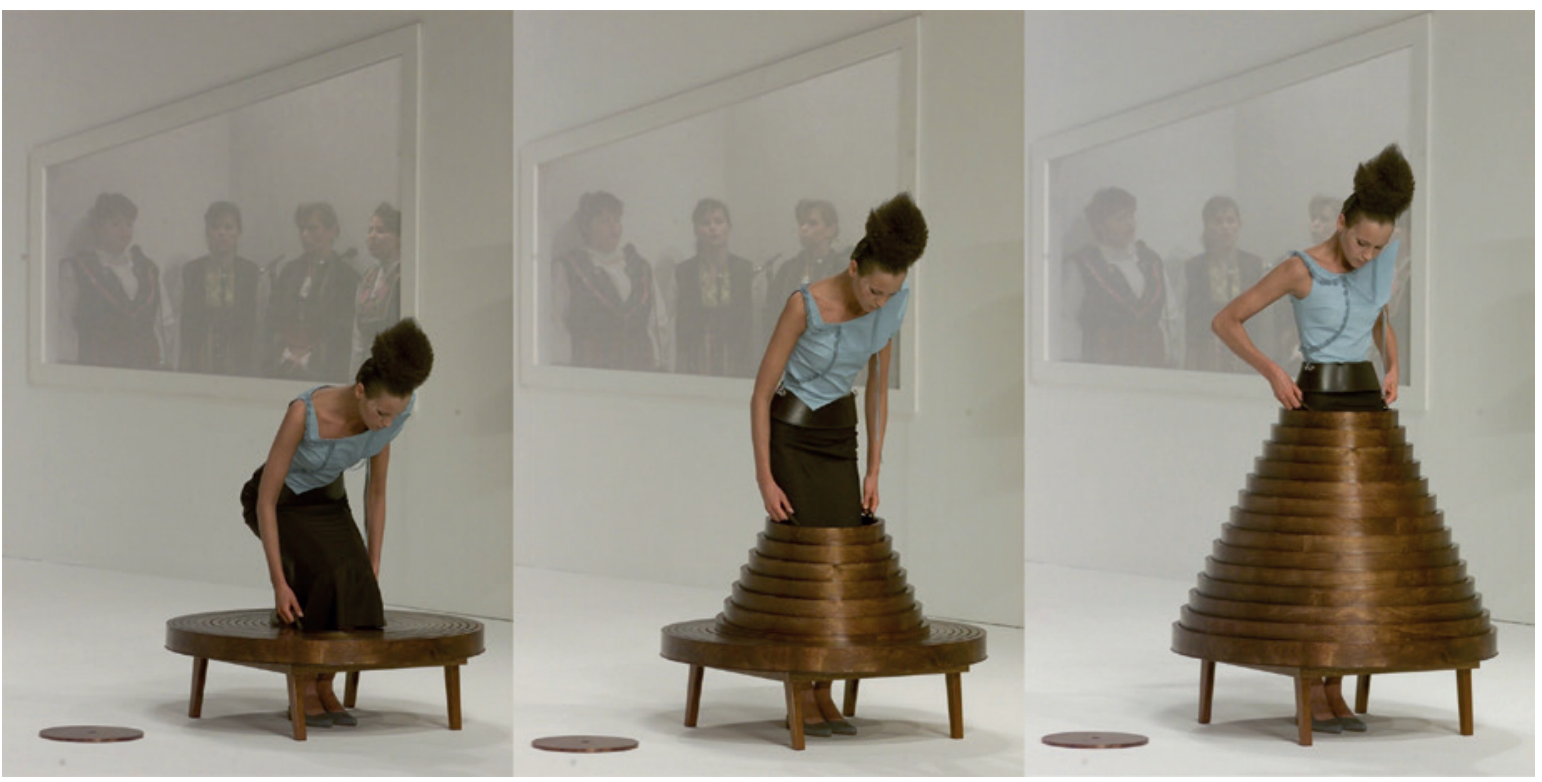

Imagen11. Salvador Dalí y Elsa Schiaparelli. Sombrero zapato, 1937-1938.

Imagen12. Imagen ficha técnica con representación de dibujo técnico de prenda, colección Habitar, 2016.

Recordamos que no es la intención ni del docente ni del discente en formación, ser un especialista en Moda, para eso ya existen estudios específicos. Lo interesante de esta investigación es conocer aplicaciones laterales y trasversales del Dibujo Técnico en otras disciplinas y, así, despertar en el estudiante el interés por la misma. En el caso de la Moda, no solo por la técnica, estética o posibilidades contemporáneas de creación, sino por el interés intrínseco que posee hacia el estudiante. La moda no es solo glamour, también es rechazo cuando no se alcanza lo que la sociedad instaura por normalidad, también son complejidades y estereotipos. Es una herramienta de diferenciación y personalidad, como se puede observar en las diferentes tribus urbanas tan populares en la adolescencia. La moda posee un fuerte carácter social que puede resultar atractivo y peligroso; y, con la excusa del dibujo técnico, el estudiante reflexiona sobre el uso de las diferentes prendas y su relación con la sociedad.

A través de este contacto con el Surrealismo se resaltan principios tan importantes en la creación, pero tan poco valorados en el Dibujo Técnico, como la casualidad y el papel del azar, imprescindibles motores de creación (Palmegiani, 2018). 


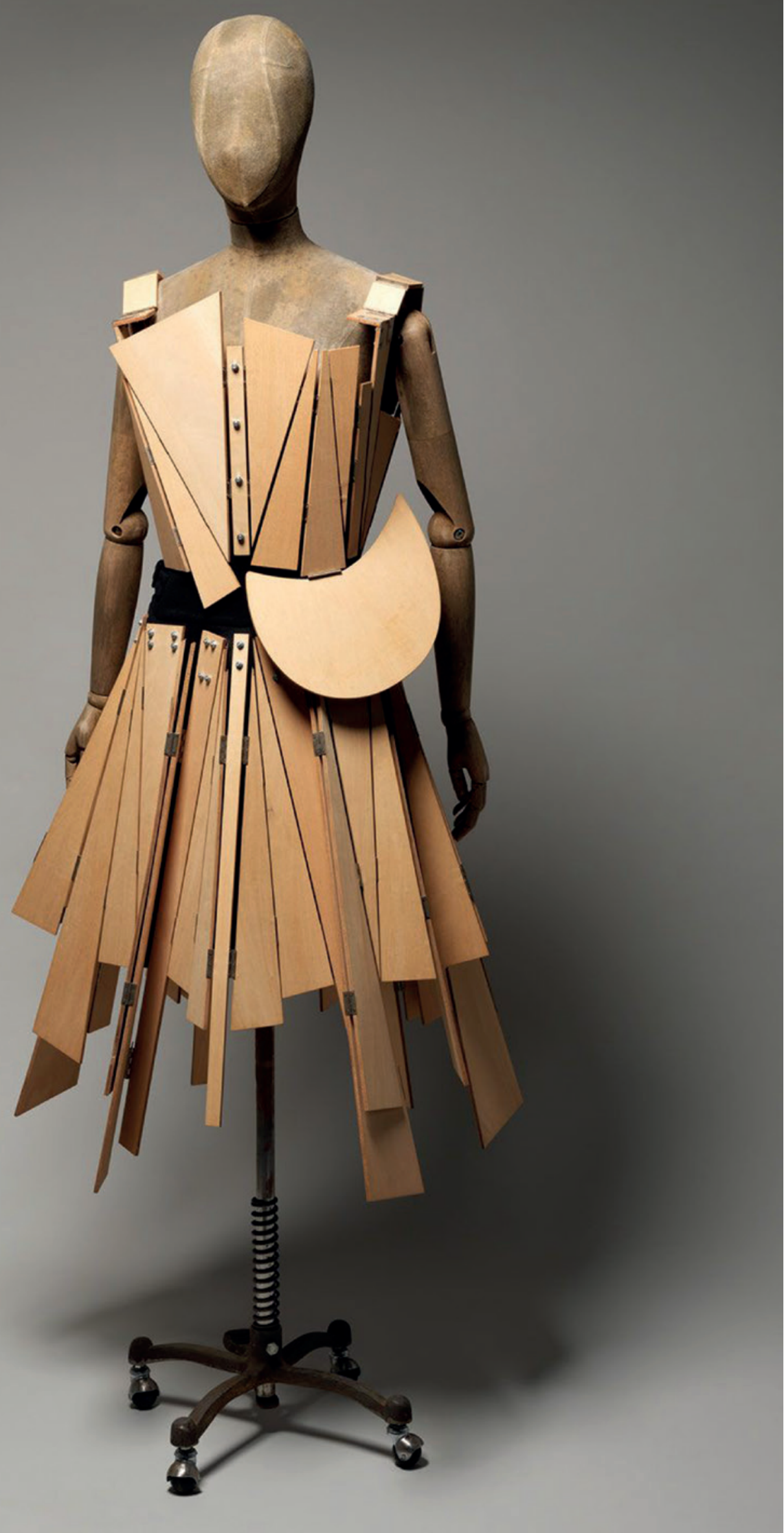

Imagen13. Yohi Yamamoto. Chaleco y falda de madera, 1991 


\section{EL AULA COMO LABORATORIO DE EXPERIMENTACIÓN EN LA FORMACIÓN DEL DOCENTE}

Se desglosan en dos bloques las diferentes etapas que dan forma a la propuesta y ayudan a aprender a habitar el aula como un laboratorio experimental donde el espacio, el individuo y los conceptos se transforman (Mesías-Lema, 2017, 2019).

\section{Raúl Molino. El espacio y su representación dentro y fuera de la creación. Habitar}

Bajo una metodología basada en entender el aula como un laboratorio de creación, se invitó al artista y diseñador de moda Raúl Molino, graduado en Diseño de Moda y Diseño de Interiores en la Escuela de Arte de Granada. La colaboración centra su interés en su colección llamada Habitar, con la que fue galardonado con el primer premio en Pasarela Fortuny (2016).

La importancia de aprovechar esta contribución al proyecto de investigación educativa en el Dibujo Técnico versa en la utilización del lenguaje de la arquitectura y la naturaleza en nuevas estructuras habitables vinculadas al concepto arquitectónico de hogar. A nuestro alrededor, en la naturaleza, se encuentran estructuras geométricas, fractales, que sirven de cobijo, para ocupar los espacios y trabajar en nuevas representaciones de los mismos, como pueden ser las alas de las mariposas, las conchas o las betas de los troncos de los árboles.
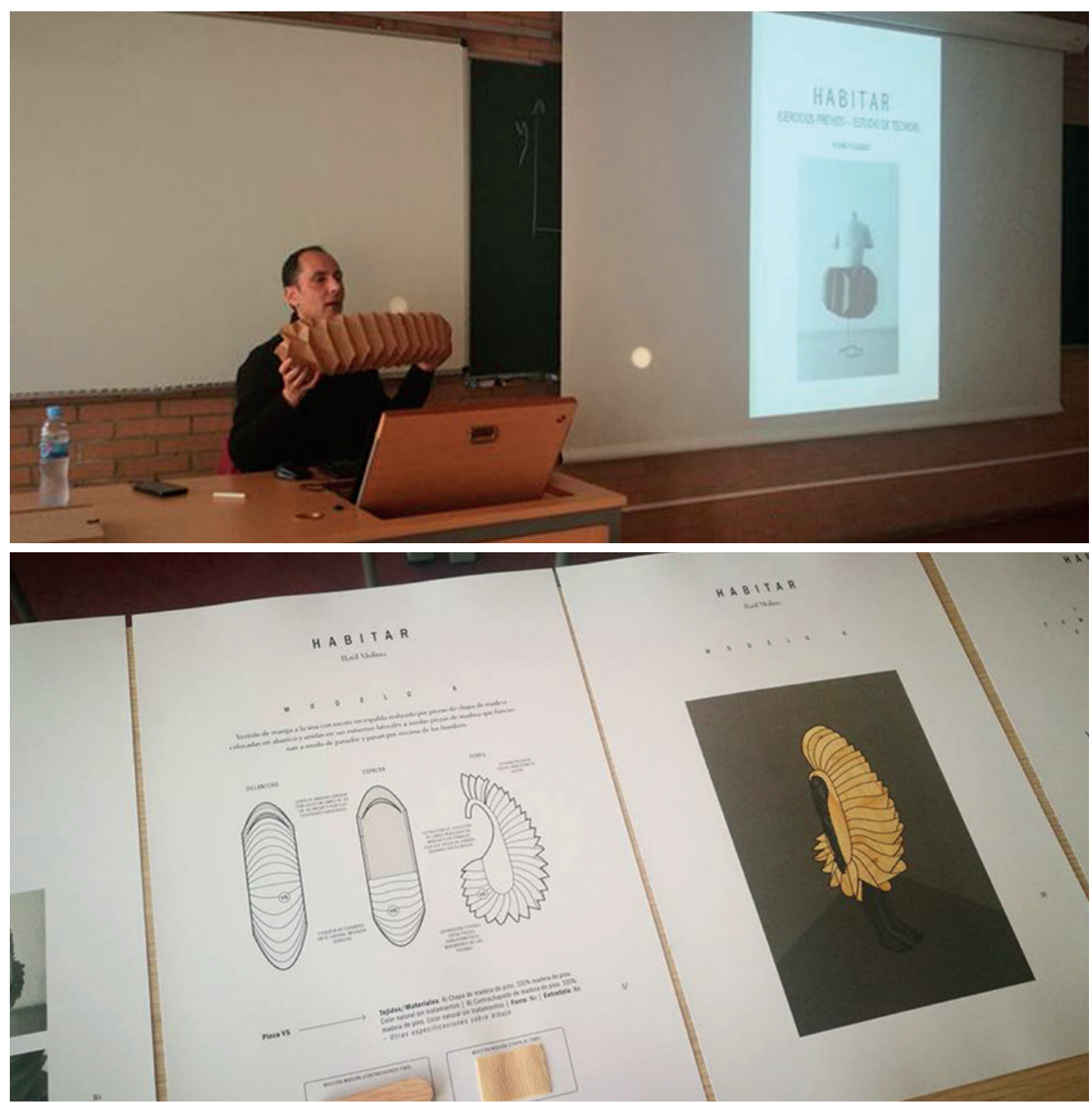

Imagen 14. Imagen extraída del seminario-taller realizado por Raúl Molino en la asignatura "Aprendizaje y enseñanza del dibujo técnico", Imagen 15. Raúl Molino. 2016. Imagen ficha técnica con representación de dibujo técnico de prenda, colección Habitar. 
Habitar propone una nueva forma de comunicación llena de movimiento y armonía, con un estilo que discurre entre la arquitectura rigurosamente geométrica y la representación del espacio que ocupa el cuerpo dentro y fuera de la producción. Con este tipo de propuestas se demuestra al alumnado cómo se pueden tratar contenidos transversales a través del binomio dibujo técnico - moda. Y la importancia, no solo de que el discente sea partícipe del mundo artístico con visitas a museos, galerías de arte o foros de debate, sino también el valor que supone la intervención de artistas y creativos en el aula. Así, el artista, el docente y el alumnado no solo ocupan o habitan un espacio educativo, además experimentan desde su propia implicación y relación con las demás personas, acto que sin duda enriquece los conocimientos de la materia (Mesías-Lema, 2019).

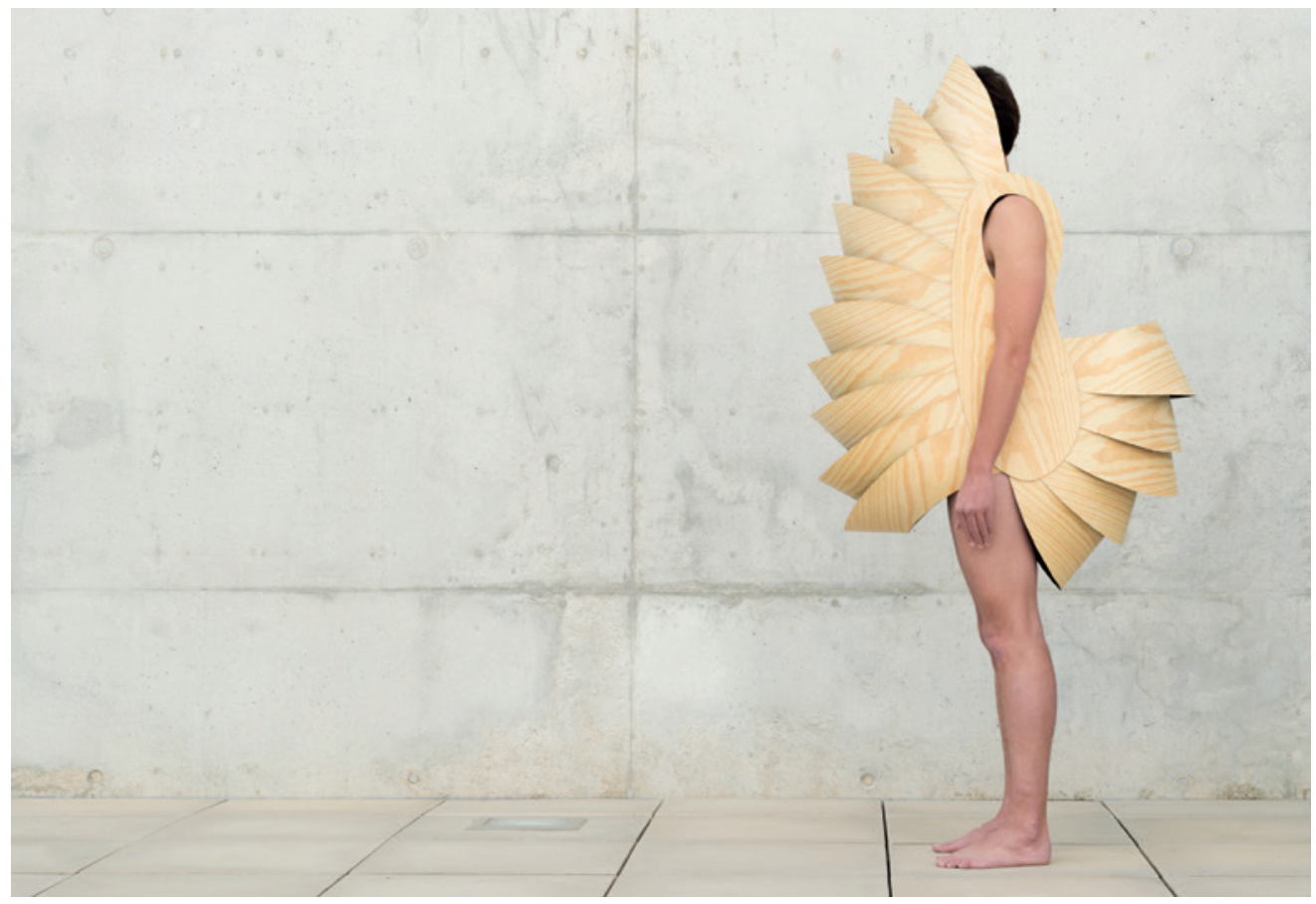

Imagen 16. Raúl Molino. 2016. Colección Habitar.

Raúl Molino también conecta lo técnico con lo artístico para conseguir que la indumentaria que produce sirva de reflexión hacia nuestra identidad, nuestra conciencia de reflexión que nos lleva a espacios habitables vitales e inmediatos. Se trata de producciones artísticas que, partiendo del Dibujo Técnico, sirven como herramienta de cambio social, cultural y, casi, por ende, también político.

\section{Método y resultados}

La siguiente propuesta es el resultado de una investigación-acción basada en las artes que ha evolucionado adaptándose a las necesidades del currículum y los intereses del alumnado con edades comprendidas entre veintitrés y cuarenta y dos años. El número de alumnos y alumnas en ambas participaciones ha sido veintitrés (curso 2017/2018) y diecinueve (curso 2019/2020). Se siguió una metodología coparticipativa en la cual docente, discente y colaborador, de forma simultánea, desarrollaban experiencias activas y aproximaciones al mundo de la moda a través de fotografías previas que habían realizado del Campus de la Universidad de Almería y que habían manipulado con anterioridad como si de los Universos de Escher se tratase.

Los espacios utilizados para la experiencia didáctica han sido el aula específica de Dibujo del Aulario del Campus y los pasillos comunes, que han permitido trabajar en un soporte más amplio que las mesas propias del aula. Al trabajar parte del desarrollo 
sobre el suelo el alumnado consigue una visión más completa del trabajo realizado. Al salir del aula se ha comprobado que el discente conecta mejor con la propuesta, consiguiendo así romper con el espacio rutinario de las clases y activar su atención y ganas de experimentar.

Los tiempos requeridos para llevar a cabo la propuesta han sido:

Principios básicos de representación espacial: cinco horas (dos sesiones).

Colaboración artística de Raúl Molino: dos horas y treinta minutos (una sesión).

Complementación teórica de referentes artísticos y conceptos de moda: dos horas y treinta minutos (una sesión).

Intervención del alumnado, desarrollo de la propuesta: cinco horas (dos sesiones).

El tiempo total de horas para desarrollar la propuesta ha sido de quince, divididas en sesiones de dos horas y media cada una. La experiencia se ha realizado en un total de tres semanas.

Estos tiempos podrían sufrir modificación al adaptarse a la Enseñanza Secundaria, ya que los conocimientos previos de Dibujo Técnico en el alumnado del Máster son dispares a los que posee el alumnado de Secundaria, por lo que sería recomendable emplear más sesiones en los bloques teóricos referidos a la representación espacial.

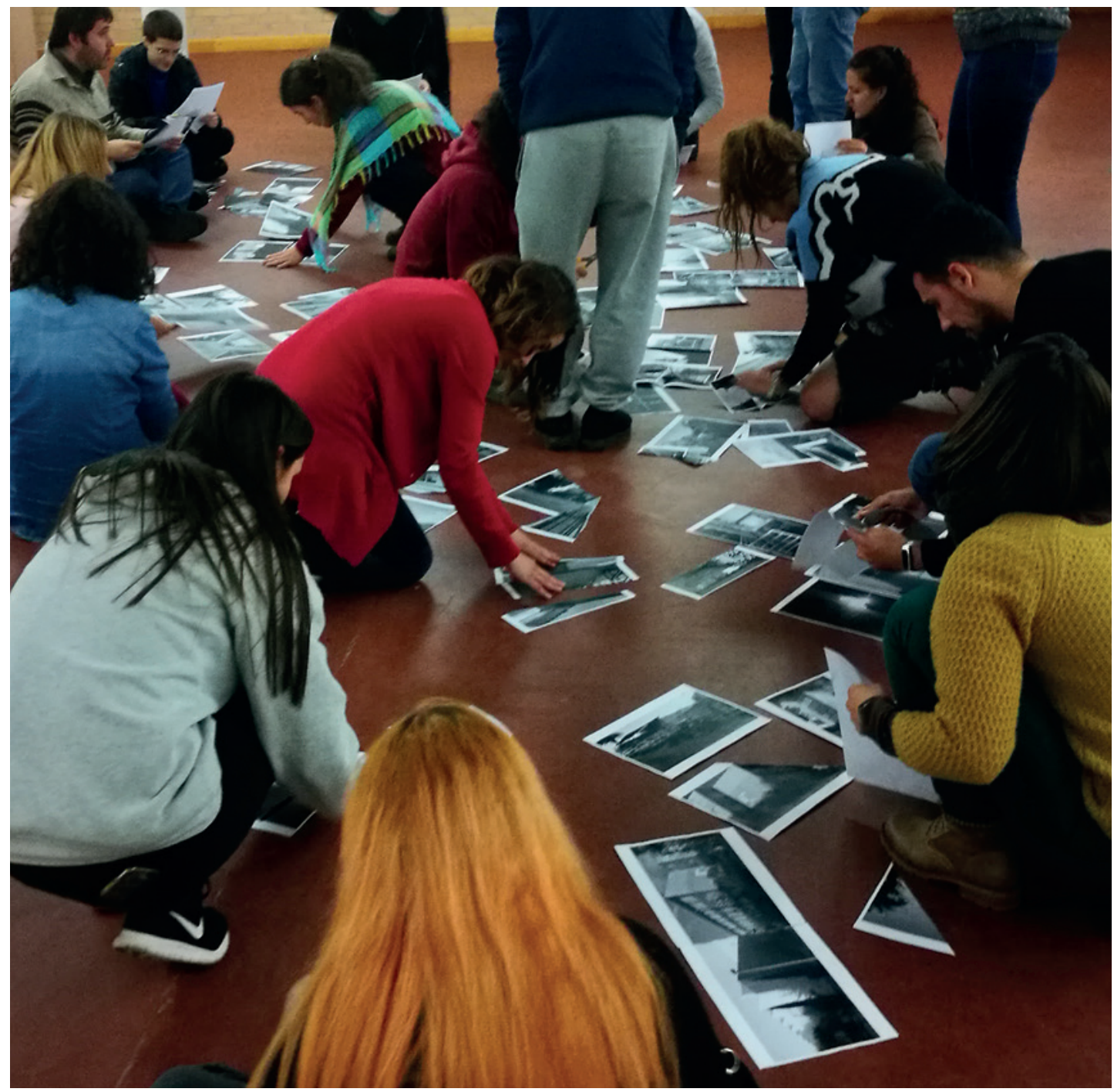


A continuación, se detallan mejor las distintas acciones de conocimiento y producción:

$1^{a}$ acción: El alumnado realiza fotografías, que posteriormente saca impresas en blanco y negro, de los distintos edificios que componen el campus de la Universidad de Almería, siendo válidas tanto las fotografías del exterior como del interior de las construcciones. En estas derivas fotográficas del campus se deben localizar los distintos puntos de fuga, la línea de horizonte, el centro de visión, la línea de tierra y puntos de vista (interior, aéreo, ojo de pájaro), potenciando el dibujo a mano alzada. Este primer acercamiento servirá de repaso de lo aprendido con anterioridad en la materia.

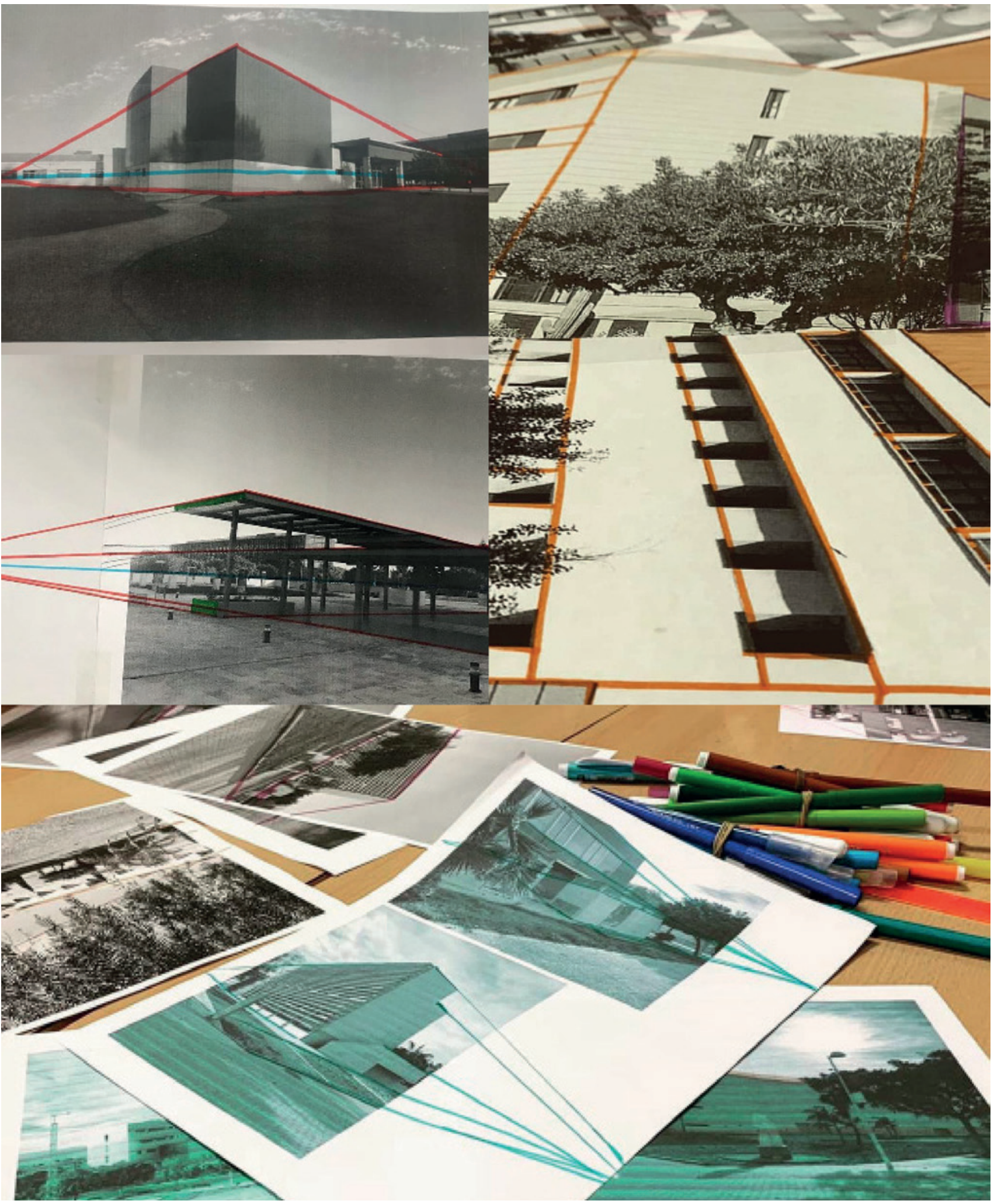

Imagen 18. Ejercicios realizados por el alumnado del Máster en profesorado de Educación Secundaria durante el curso académico $2019 / 20$ 
$2^{a}$ acción: En esta etapa del juego, si se permite denominar así al trabajo que se va realizando, el alumnado debe rasgar, romper y doblar las fotografías a su antojo, pero teniendo en consideración la obra de M. C. Escher, sus figuras imposibles, teselados y mundos imaginarios que rompen con la perspectiva racional. A través de un trabajo colaborativo se construyen composiciones mediante la técnica del collage y sobre superficie plana, atendiendo a la primera y segunda dimensión.
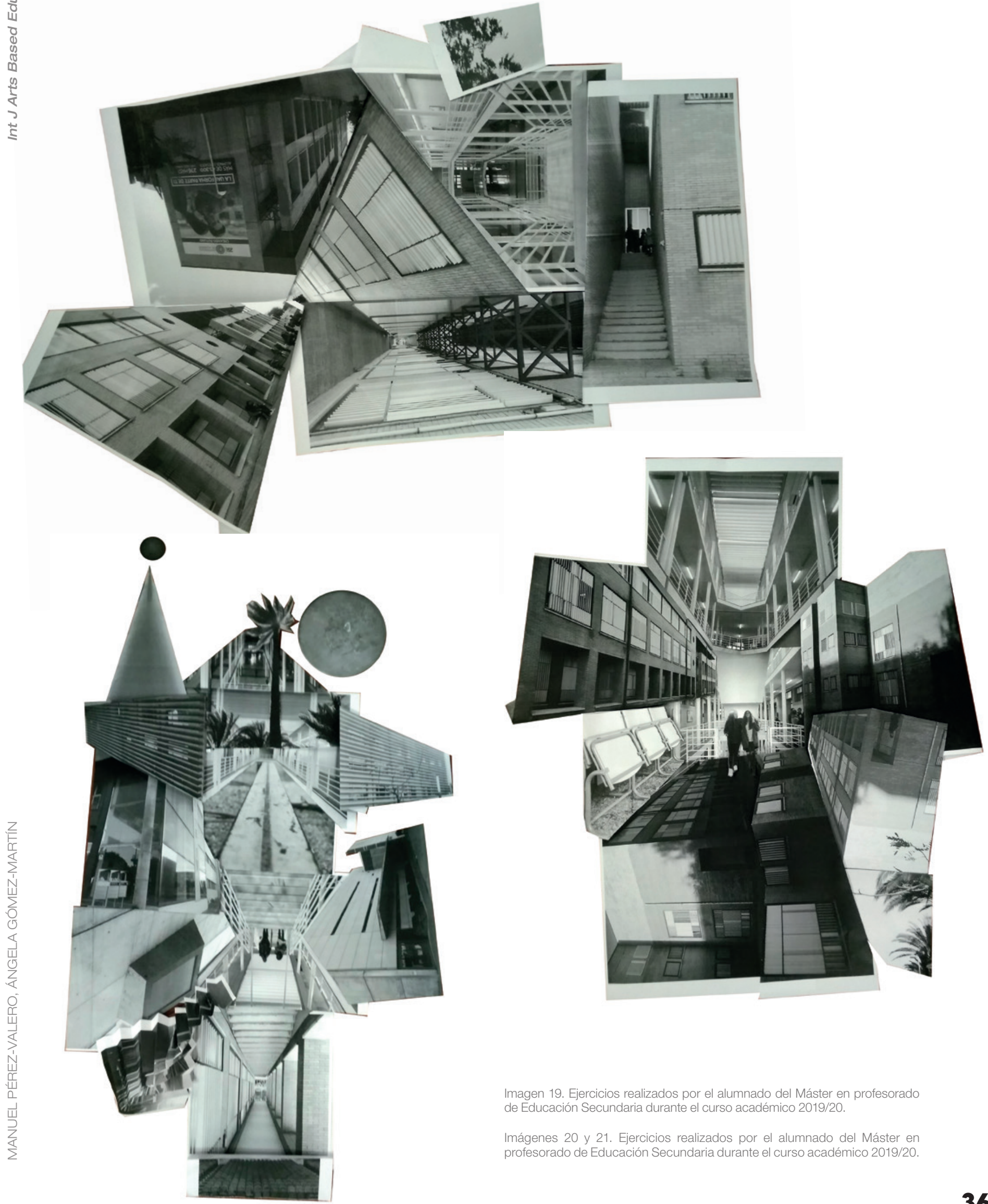

Imagen 19. Ejercicios realizados por el alumnado del Máster en profesorado de Educación Secundaria durante el curso académico 2019/20. 


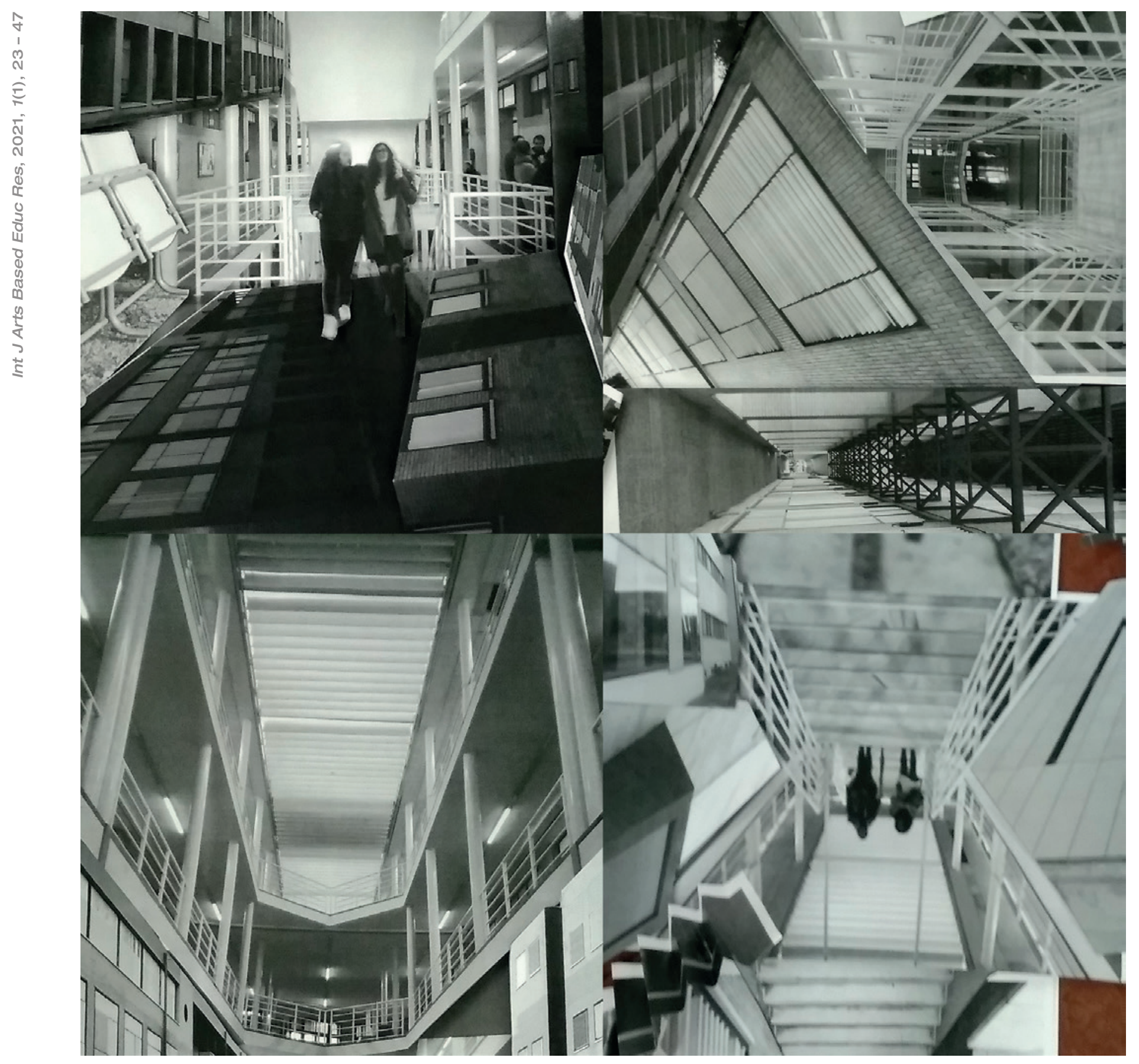

Imagen 22. Ejercicios realizados por el alumnado del Máster en profesorado de Educación Secundaria durante el curso académico 2019/20. 
$\mathbf{3}^{\mathbf{a}}$ acción: Tras finalizar las dos acciones anteriores ahora es el momento de realizar una prenda o complemento relacionado con el mundo de la moda, teniendo como referente la colaboración del diseñador Raúl Molino y los artistas nombrados en el marco teórico. En este caso en concreto se optó por la elaboración de un único tocado o sombrero de forma colaborativa por todo el alumnado, dotando de tridimensionalidad a los collages realizados en la segunda acción.

Se ha trabajado atendiendo a creaciones surrealistas que se podrían concebir como un conjunto de procedimientos de creación-expresión que utilizan todas las fuerzas provenientes del sueño y el inconsciente (Casablanca, 2007). El ejercicio consiste en reutilizar las creaciones "escherianas" de la segunda fase y formar nuevas composiciones o estructuras casi arquitectónicas que dialoguen con el espacio ocupado y con el vacío. Sombreros y tocados que posean carácter escultórico y muestren perspectivas utópicas, absurdas, inalcanzables y experimentales. Mediante esta representación espacial se potencian capacidades tan importantes como la imaginación y la fantasía.
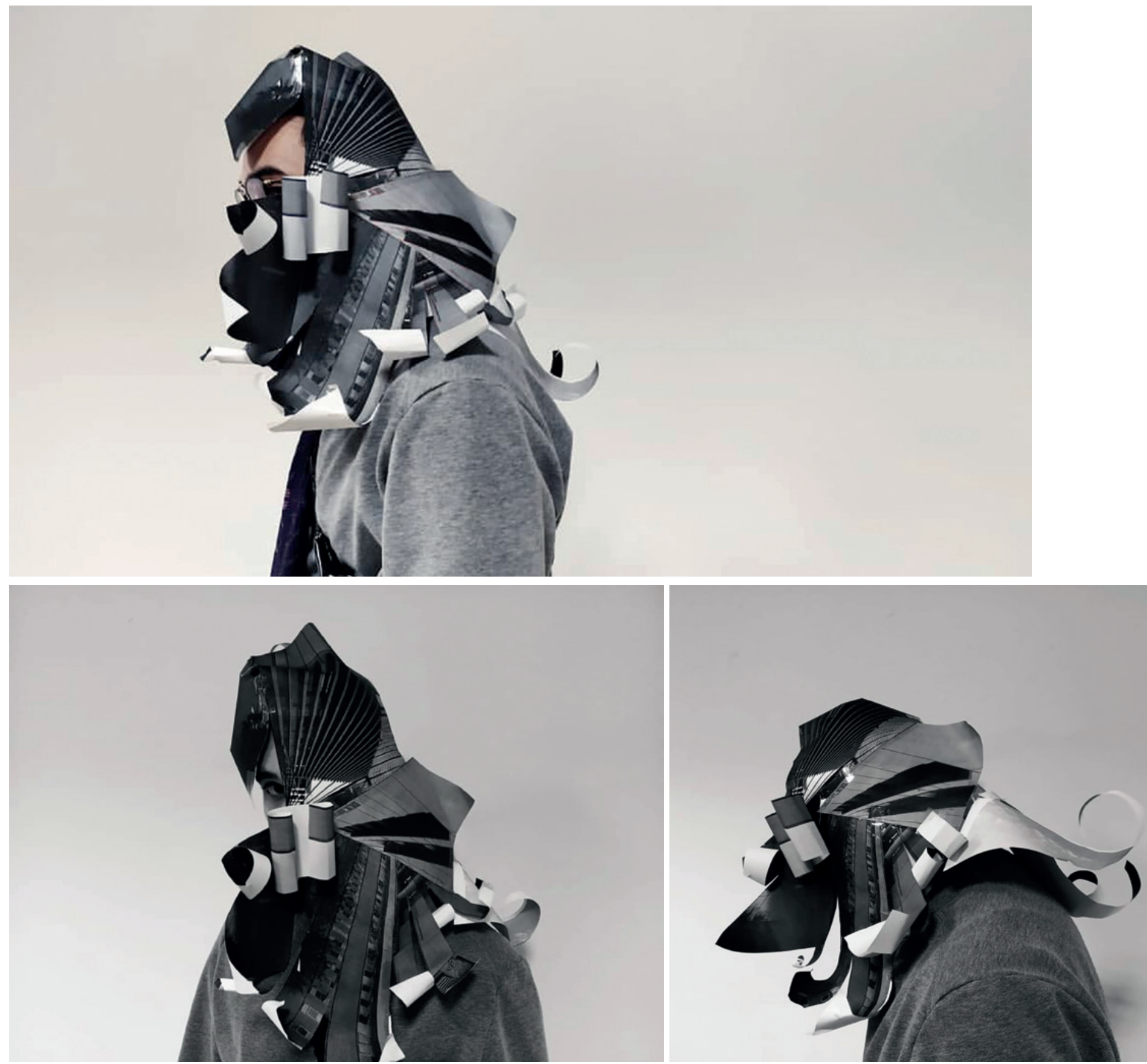

Imagen 23. Resultado final de la propuesta realizada por el alumnado del Máster en profesorado de Educación Secundaria. 2019/20. Tocado sombrero Escher Imágenes 24 y 25. Resultado final de la propuesta realizada por el alumnado del Máster en profesorado de Educación Secundaria. 2019/20. Tocado sombrero Escher. 
Como ya se conoce, enseñar arte es complejo y, por ende, evaluarlo también. El método de evaluación usado ha sido objetivo-subjetivo (aparecen elementos objetivos propuestos por el docente, que sirven de guía para el alumnado, y elementos subjetivos por parte del discente que legitiman el aprendizaje), haciendo referencia a juicios del proceso y producto, a valores flexibles y abiertos que concretan los significados. Al ser una propuesta que centra su poder en la experimentación, se valoran aspectos como el riesgo, la creatividad, la implicación, el trabajo colaborativo, por encima de resultados finales que se puedan medir numéricamente.

Como se ha señalado con anterioridad, esta propuesta se trata de una intervención en el aula, experimental y sujeta a la creatividad de los alumnos y alumnas de Máster. Se prima la experiencia a los datos rigurosos y científicos. Como propuesta de mejora, para el futuro, sería interesante como docente anticipar las necesidades de investigación que puedan surgir y plantear una recogida de datos rigurosa.

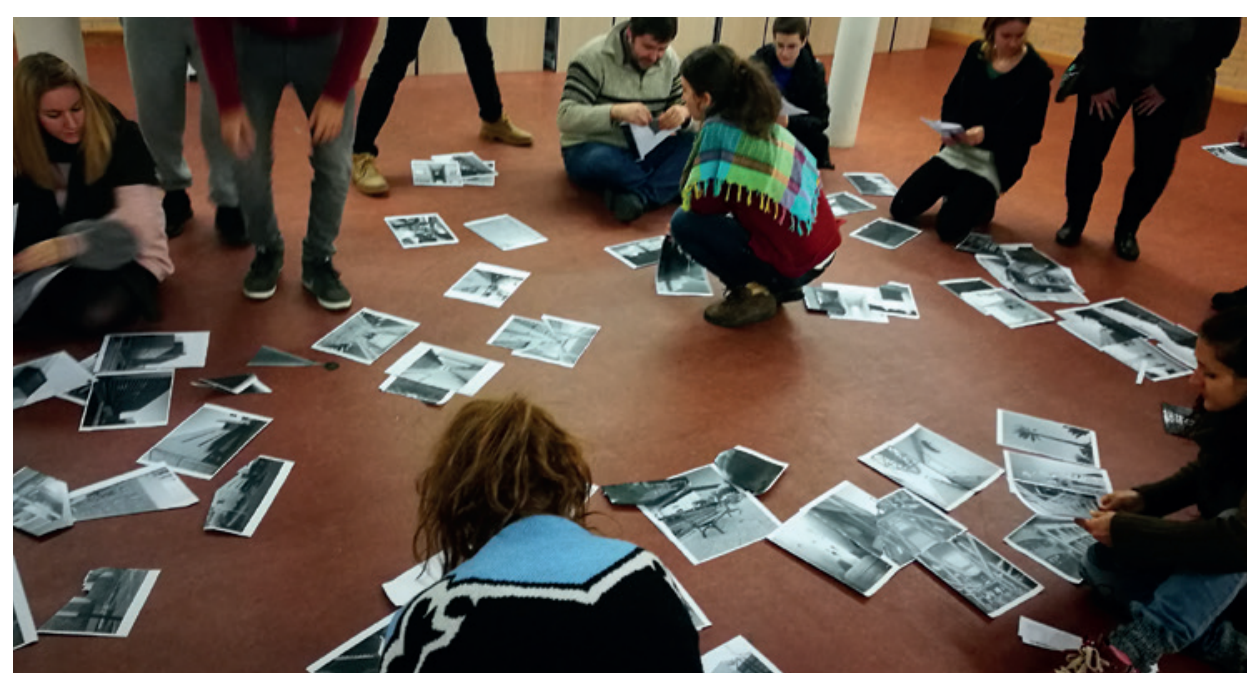

Imagen 26. Ejercicios realizados por el alumnado del Máster en profesorado de Educación Secundaria. 2017/18.

\section{EL RELATO DEL ALUMNADO SOBRE EL APRENDIZAJE VIVIDO}

En una investigación educativa basada en las artes, las voces de todas las personas que han estado vinculadas a la misma crean una polifonía que aportará diferentes puntos de vista sobre la experiencia.

\subsection{Una mirada desde dentro. Del aprendizaje académico al aprendizaje experimental}

En Secundaria, y desde mi propia experiencia, el estudio del Dibujo Técnico se centra en los cursos de primero y segundo de bachillerato de las especialidades de Ciencias, Tecnología y Artes, con estudiantes de unas edades comprendidas en su mayoría entre los dieciséis y los dieciocho años. Este alumnado no ha trabajado antes esta asignatura, por lo que se enfrenta a diferentes dificultades que Rafael Torres (2009) enumera:

- Complejidad de la materia.

- Dificultades de observación.

- Dificultades de dibujo.

- Problemas de medida.

- Problemas de comunicación y comprensión. 
Sería apropiado, desde la experiencia personal, añadir una dificultad más que será crucial para el entendimiento de la materia, que radica en la descontextualización y abstracción de los contenidos. Y es que el estudiante, al ahondar en la materia de Dibujo Técnico, fácilmente puede verse sumergido en un universo de planos y dimensiones abstractas, lo cual requiere de un nivel de desarrollo cognitivo a veces demasiado elevado para la generalidad del aula.
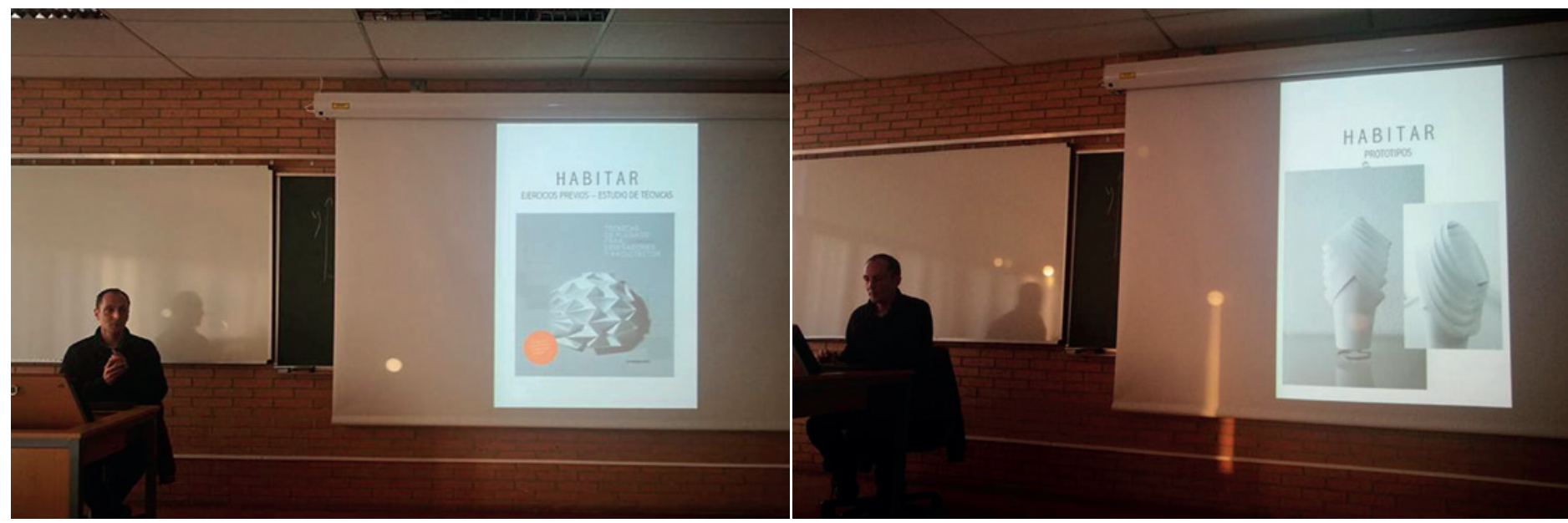

Imagen 27 y 28. Imágenes extraída del seminario-taller realizado por Raúl Molino en la asignatura aprendizaje y enseñanza del dibujo técnico del Máster en Profesorado de Educación Secundaria.

En el libro Manual de Neuropsicología, se expone que Piaget da por finalizado el desarrollo cognitivo del adolescente a los quince años, sin embargo, el autor neopiagetiano Fisher propone una última etapa del desarrollo llamada "El ciclo de las abstracciones", que se extiende de los catorce hasta los veinticinco años (Maestú, Ríos y Tirapu, 2008), entendiendo así que el alumnado podría encontrarse en pleno desarrollo de estas capacidades durante el transcurso de la materia.

Por otra parte, el Dibujo Técnico en Secundaria se centra obsesivamente en la resolución de varios ejemplos de ejercicios, convirtiéndose en un entrenamiento forzoso, con el fin de superar una prueba final, la EVAU (Selectividad). La constante presencia de esta prueba en el día a día de los estudiantes y la dificultad de la misma pueden generar altos niveles de estrés y ansiedad, provocando un estado de Indefensión Aprendida en el alumnado frente al fracaso en el desarrollo de las actividades planteadas. Sobre la teoría de la Indefensión Aprendida, Polaino-Lorente y Vázquez (1982, p. 174) postulan que "la causa de los bajos rendimientos de los sujetos sometidos anteriormente a situaciones de incontrolabilidad reside en que han percibido tal situación y posteriormente proyectan este modo de percibir a otras situaciones". En este caso, al fracasar en una serie de resoluciones de problemas o al percibir la actividad como compleja, el alumnado asume que la totalidad de la asignatura es demasiado complicada para ellos, provocando un estado de pérdida de autoestima, pasividad y de abandono de la misma.

El perfil de los componentes del aula, que requieren de esos conocimientos para sus futuros estudios universitarios, es muy amplio, desde profesiones de ciencias como ingenieros o arquitectos, a líneas más vinculadas con la actividad artística, como diseñadores de producto, de interiores o de moda. Teniendo esto en cuenta, enfocar la docencia de la materia en una suerte de ejercicios repetitivos, excesivamente técnicos y abstractos, alimenta en mayor medida el anteriormente nombrado efecto de Indefensión Aprendida, ya que "este tipo de comprensión deficitaria de la realidad o sensación de incontrolabilidad suele estar asociado a problemas como el estrés generado por las demandas escolares" (Barraza y Silerio, 2011, p. 338). 
No se puede olvidar que dicha abstracción y descontextualización, tan excesivamente técnica, despoja al aprendizaje del Dibujo Técnico de los elementos de creatividad o trabajo colaborativo, entre otras habilidades tan requeridas para el alumno y alumna en su futuro desarrollo. Y que además está contemplado en el Real Decreto (1105/2014, de 26 de diciembre), por el que se establece la necesidad de afianzar el espíritu emprendedor con actitudes de creatividad, flexibilidad, iniciativa, trabajo en equipo, confianza en uno mismo y sentido crítico.

Para resolver estas problemáticas, se considera que una revisión del modelo de enseñanza de la materia es imprescindible. Por ello es necesaria la formación continua del docente en metodologías innovadoras como la que se ha planteado en la asignatura del Máster que nos ocupa. Mediante el trabajo colaborativo, de experimentación y el uso de las TICs, tan olvidadas en la mayoría de los centros, se ayudaría a los estudiantes, nativos digitales, a conectar con los contenidos en su propio lenguaje. Por otra parte, la revisión del modelo de materia debe ser íntegra, desde el enfoque de la misma, el trabajo del docente y sobre todo los métodos de evaluación, ya que lo que se evalúa del Dibujo Técnico, en pruebas como la EVAU, es tan limitado a la vez que complejo que no permite al docente ni al estudiante tomar otros caminos dentro de la programación.

Con este escenario de experiencia personal, no demasiado gratificante como estudiante, me reencuentro con la asignatura diez años después, esta vez cursando el Máster en Profesorado de Educación Secundaria, con el fin de convertirme en docente de la misma. En dicho Máster, la asignatura se plantea desde un punto de vista transversal y creativo, dando cabida en la misma a todo tipo de perfil de estudiante y enfocando el contenido de lo abstracto en lo tangible, dirigiéndose a doctrinas y profesiones reales que hacen uso del dibujo técnico en su trabajo diario.

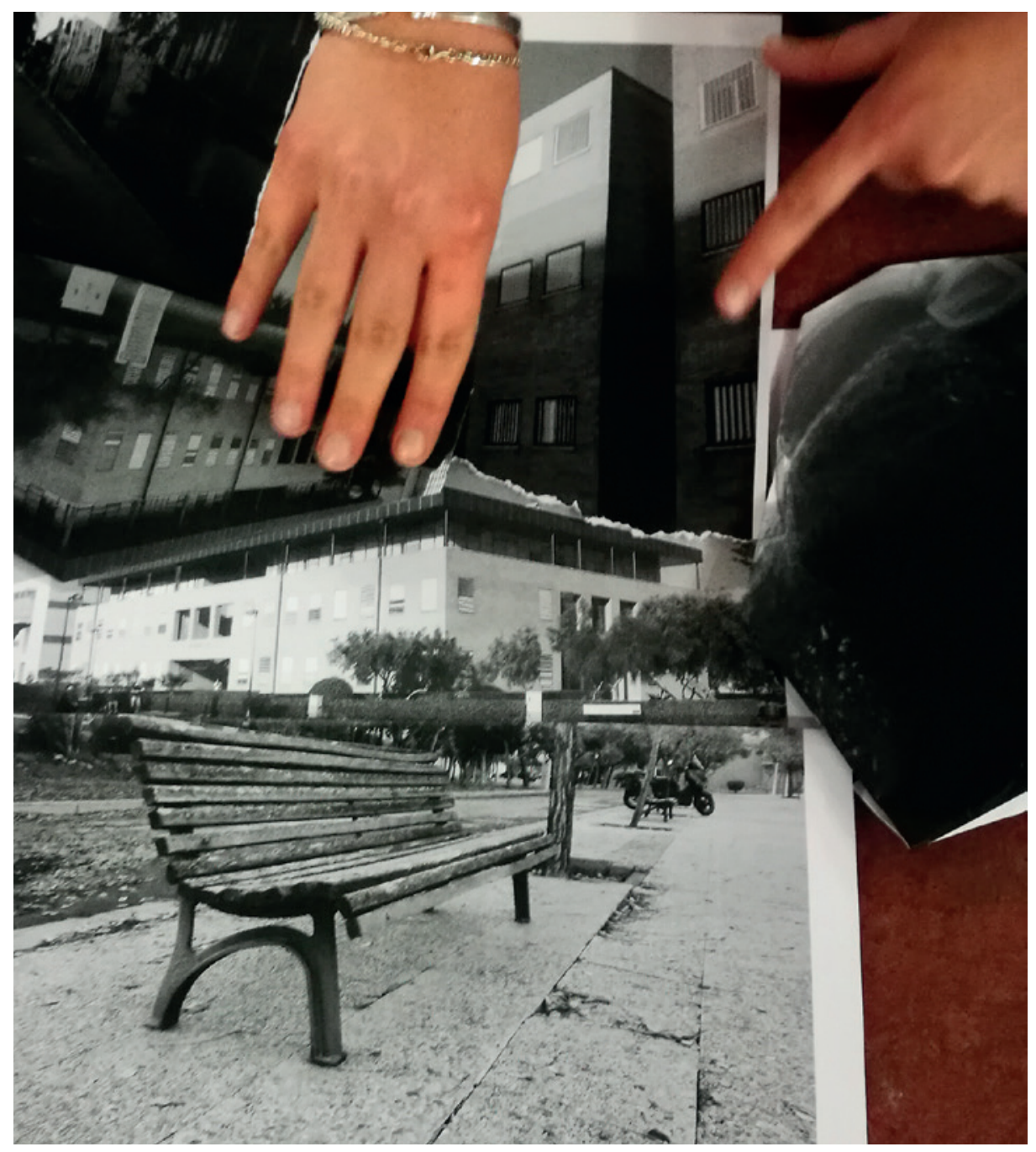

Imagen 29. Ejercicios realizados por el alumnado del Máster en profesorado de Educación Secundaria durante el curso académico 2017/18 
A través del dibujo técnico y el diseño de moda, el alumnado aprende la proyección de figuras tridimensionales, el trabajo con objetivos, la resolución de problemas, las modificaciones de un modelo y trabajo de croquis. Y, lo más importante, al finalizar el proyecto, puede visualizar un resultado gratificante de su trabajo y entender que la creación artística no sólo es un acto de expresión de un sentimiento, sino que también supone una vía para la motivación, una manera de trabajar la sensibilización, un camino para la adquisición de nuevos conocimientos y actitudes y también una forma de comunicación (Vanrell, 2007, p. 253).

El intentar plasmar plásticamente la realidad de aquello que nos afecta es un proceso creador que supone desarrollar una capacidad de análisis, motivada por la observación, y una capacidad de síntesis, al expresar lo transformado después de pasar por el crisol de la experiencia personal del creador.

Mediante las acciones descritas, el estudiante desarrolla una mirada crítica hacia el medio, capaz de vislumbrar perspectivas, patrones y elementos interesantes como composición en la realidad de su entorno. Desarrolla habilidades de trabajo en equipo e interioriza conceptos de una manera dinámica y creativa mediante la experimentación. En cualquier otro caso, a través de la representación clásica de perspectivas mediante el dibujo, el proceso habría sido más lento y limitado. Además, se fomenta la práctica de las TICs en el aula mediante el uso del celular, ya que, como indican Basilotta, GarcíaValcárcel y López (2014), permiten mejorar la comunicación y el trabajo entre alumnos y alumnas, destacando siete ventajas: eficiencia, valores morales, intercambio de información, innovación, limitación de duplicidades, viabilidad y unidad. También se ha relacionado con un incremento del aprendizaje al favorecer una mayor interacción entre el profesorado y el alumnado.

En las acciones desarrolladas se trabaja el dibujo técnico de manera tangible y contextual, lo que permite al estudiante comprender e interiorizar conceptos que posteriormente podrá aplicar al dibujo técnico clásico. Educación, dibujo técnico y moda convergen en la asignatura y ofrecen una experiencia que, como futuro profesorado, es imprescindible conocer y tener en valor.
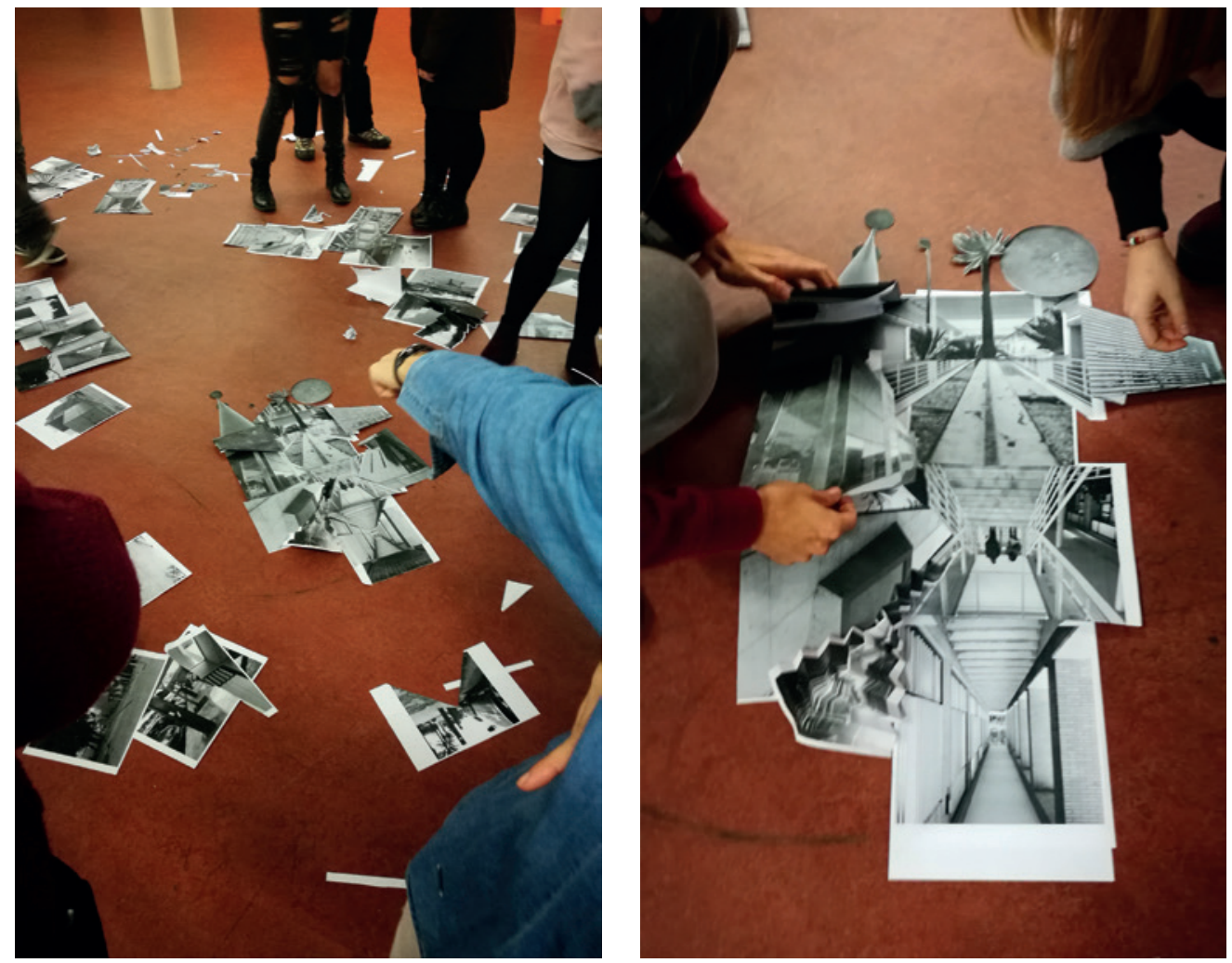

Imágenes 30 y 31. Ejercicios realizados por el alumnado del Máster en profesorado de Educación Secundaria durante el curso académico 2017/18 


\subsection{Aprendizaje adquirido durante la investigación-acción}

Por otra parte, en lo relativo al desempeño de la actividad planteada en el Máster y la metodología de la misma, como alumna considero que este tipo de enseñanza de la materia, transversal y creativa, es crucial para aprender a explorar y explotar las posibilidades del Dibujo Técnico; así como dotar al futuro profesorado de Educación Secundaria de herramientas metodológicas novedosas que lleven la enseñanza a un estándar de calidad muy superior al actual. El aprendizaje, desde la formación docente del Dibujo Técnico influenciado por otras disciplinas, como la Moda y el Arte, es fundamental para enriquecer la experiencia del alumnado en Secundaria.

Gracias a lo aprendido poseo las herramientas suficientes para adaptarme a este modelo de enseñanza, el cual considero que debería ser modelo en el futuro para todos los centros educativos. En este modelo de enseñanza por descubrimiento, mi tarea de docente es la de ser guía del aprendizaje y procurar que cada estudiante logre desarrollarse en la materia lo máximo posible, frente al modelo de profesor como fuente de información que plantea la educación tradicional. El profesor plantea el desarrollo de la actividad y propicia las situaciones, como en el diseño de la actividad de moda y dibujo técnico; y el discente es el que experimenta, analiza los resultados y adquiere los aprendizajes de sus propias experiencias.

Esta metodología de aprendizaje adquirida en el transcurso de la asignatura, actualmente es aplicada durante mi actividad docente. Por fortuna, en el centro educativo Escuela Superior de Arte y Diseño de Andalucía, donde imparto clases de Diseño Gráfico, apuestan por una pedagogía transversal y por proyectos, donde todas las materias trabajan conjuntamente en el desarrollo de las tareas. Dichos proyectos tienen un propósito real y contextualizado, trabajando el alumnado de manera conjunta con las empresas. Anualmente también se trabaja un proyecto transversal para todas las disciplinas de diseño que se imparten en el centro.

\section{CONCLUSIONES}

La propuesta docente se ha tomado como punto de partida para una futura investigación educativa basada en las artes a través de la aplicación de conocimientos vinculados al dibujo técnico. La metodología llevada a cabo en el aula ha tenido buena aceptación por parte del alumnado, el futuro profesorado, por lo que se podría confirmar que es un vehículo de aprendizaje creativo con carácter investigador. Durante los procesos de enseñanza puestos en práctica se ha desarrollado y potenciado la curiosidad, el espíritu crítico, la mirada.

El método utilizado se fundamenta en el diálogo, la comunicación y la reflexión; por lo que se consigue que un trabajo de una materia como es Dibujo Técnico lleve al alumnado a comprender que ya no existen representaciones absolutas. Hay que enseñar a detectar la diferencia, a analizar lo distinto y deconstruir los estereotipos. Utilizando métodos tradicionales de representación se comprende que el dibujo técnico sirve como puente para llegar a diferentes vías y disciplinas, a conocer, aunque no dominar, universos tan apasionantes y estimulantes en el discente como la moda.

La experiencia ha despertado en la formación del profesorado de Secundaria el interés por promover el Dibujo Técnico como estimulante, que infle la imaginación por medio de conocimientos previos tradicionales; al mismo tiempo que se presta al servicio de las necesidades educativas de nuestro tiempo en la Enseñanza Secundaria, donde las experiencias - clases - deben suponer, no solamente una investigación con un fuerte perfil práctico, sino también un crecimiento personal que supere la insustancialidad de lo técnico y aquellos límites que nos impone lo académico. Y es que, tal y como defiende Arthur D. Efland (2003, p. 17), teniendo en cuenta la visión moderna de nuestra sociedad, debe ser premiada la capacidad de aprehender tus propios estados emocionales y 
saber revelarlos o representarlos a través de creaciones que reconsideren el valor de originalidad y expresión personal.

Ha sido el momento de dar al alumnado aquello que yo había echado de menos haber recibido en mi formación. Y siendo esto una opinión personal, no debemos olvidar en nuestra carrera profesional que el buen docente es aquel que hace interesante la vida y no la educación.

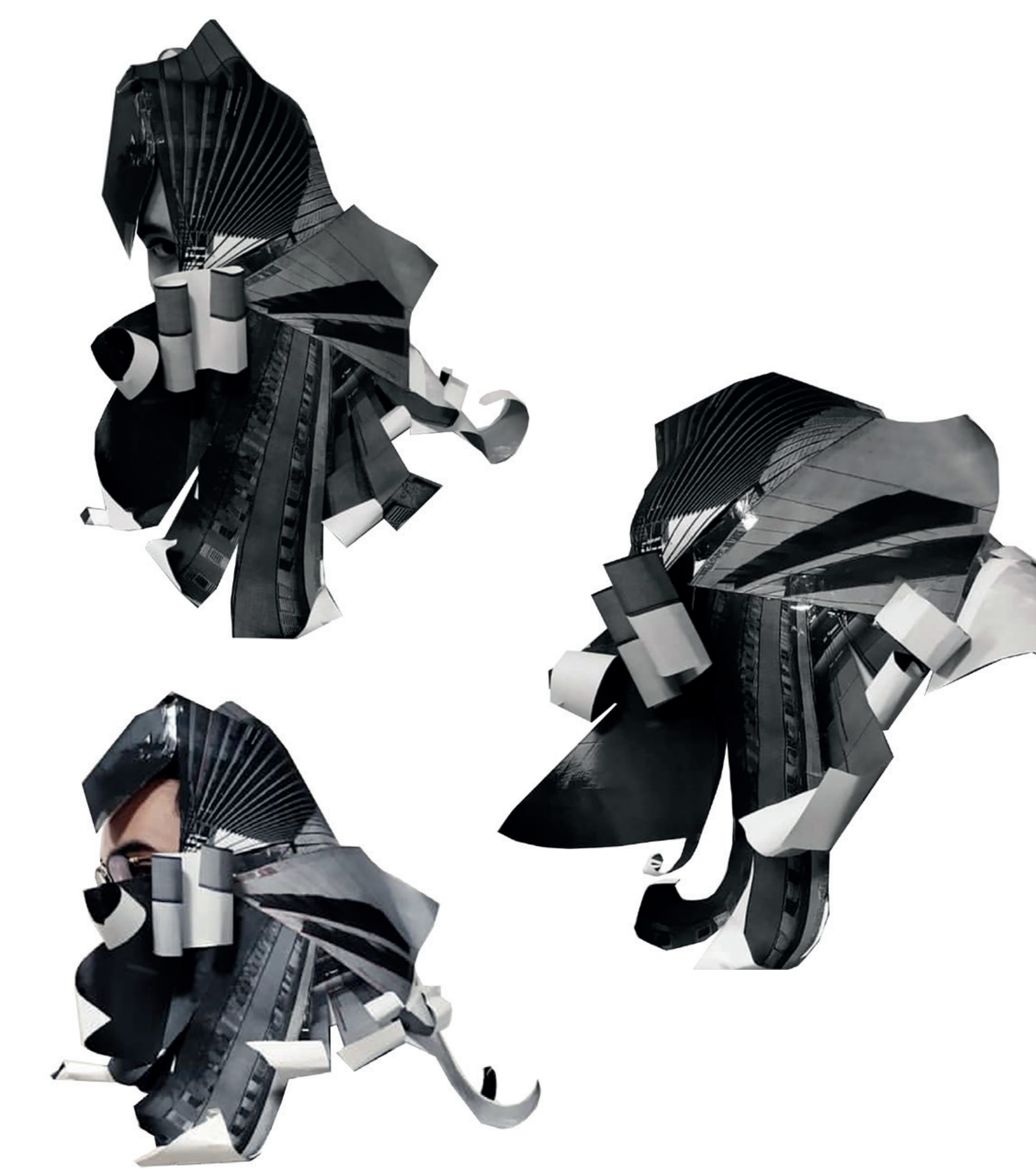




\section{REFERENCIAS BIBLIOGRÁFICAS}

Arheim, R. (2005). Arte y percepción visual. Madrid: Alianza Editorial.

Barraza, A. y Silerio, J. (2012). Indefensión escolar aprendida en alumnos de educación media superior y su relación con dos indicadores del desempeño académico. Psicogente, 15 (28), 337-347. http://revistas.unisimon.edu.co/index.php/psicogente/ article/view/1880,

Baudot, F. (2003). Moda y surrealismo. Madrid: H. Kliczkowski.

Berrater, B., Santos, J. D. y Ferrater, C. (comp.) (2011). M.C. Escher. Infinite Universes. (Exposición celebrada en Granada, Parque de las Ciencias, del 29-III-2011 al 08-I-2012). Granada: Gráficas Alhambra.

Bruner, J. (2001). El proceso mental en el aprendizaje. Madrid: Narcea.

Caeiro-Rodríguez, M. (2018). Aprendizaje Basado en la Creación y Educación Artística: proyectos de aula entre la metacognición y la metaemoción. Arte, individuo y sociedad, 30 (1), 159-177.

Camargo, A. y Hederich, C. (2010, diciembre). Jerome Bruner: dos teorías cognitivas, dos formas de significar, dos enfoques para la enseñanza de la ciencia. Psicogente, 13 (24), 329-346.

Casablanca, L. (2007). La moda como disciplina artística en España. Jesús del Pozo y la generación de los nuevos creadores [Tesis Doctoral]. Universidad de Granada.

D. Efland, A., Freedman, K. y Stuhr, P. (2003). La educación en el arte posmoderno. Barcelona: Editorial Paidós.

Fernández, A. y Martín, G. (2009). Dibujo para diseñadores de Moda. Barcelona: Parramón.

García-Valcárcel. A, Basilotta, V. y López, C. (2014). Las TIC en el aprendizaje colaborativo en el aula de Primaria y Secundaria. Comunicar, XXI (42), 65-74. https://www.redalyc. org/articulo.oa?id=158/15830197008.

Gómez Molina, J. J., Cabezas, L. y Bordes, J. (2003). El manual de dibujo. Estrategias de su enseñanza en el siglo XX. Madrid: Cátedra.

López, V (coord.) (2009). Perspectiva. Ciencia y magia de la representación. (Exposición celebrada en Granada, Parque de las Ciencias, diciembre 2008 a septiembre 2099). Granada: Gráficas Alhambra.

Lurie, A. (2002). El lenguaje de la moda. Una interpretación de las formas de vestir. Barcelona: Editorial Paidós.

Maestú, F., Ríos, M. y Tiraou, J. (2008). Manual de Neuropsicología (2ª ed.). Barcelona: Viguera.

Mesías Lema, J. M. (2017). Art Teacher Training: a photo essay. International Journal of Education through Art, 13 (3), 395-404. https://doi.org/10.1386/eta.13.3.395 1.

Mesías Lema, J. M. (2019). ARTISTAS HABITANTES: una metodología contemporánea, participativa y colectiva en Educación Artística. Observar 2019. 13, 74-104. https:// www.observar.eu/ojs/index.php/Observar/article/view/104.

Mesías Lema, J. M. (2019). Educación artística sensible. Cartografía contemporánea para arteducadores. Barcelona: Editorial GRAÓ.

Pallasmaa, J. (2014). Los ojos de la piel: la arquitectura y los sentidos ( $2^{a}$ ed.). Barcelona: Gustavo Gili. 
Palmegiani, M (2018). Elsa Chiaparelli y su relación con el Surrealismo. Revista anual de Historia del Arte. Liño, 24, 73-84.

Polaino-Lorente, A. y Vázquez, C. (1982). La indefensión aprendida: ¿Un modelo experimental de depresión? Revista del Departamento de Psiquiatría de la Facultad de Medicina de Barcelona, 3, 173-195. http://opendata.dspace.ceu.es/handle/10637/1905.

Real Decreto 1105/2014, de 26 de diciembre, por el que se establece el currículo básico de la Educación Secundaria Obligatoria y del Bachillerato. Boletín Oficial del Estado, núm. 3, del 3 de enero de 2015. https://www.boe.es/buscar/act.php?id=BOE-A-2015-37.

Squicciarino, N. (2012). El vestido habla, consideraciones psico-sociológicas sobre la indumentaria. Madrid: Cátedra, Signo e imagen.

Szkutnicka, B. (2010). El dibujo técnico de moda paso a paso. Barcelona: Gustavo Gili.

Torres, R. (2009) Aplicación de la metodología Interactiva del dibujo técnico en la enseñanza secundaria con el programa Cabri 2D- 3D. [Tesis Doctoral]. Universidad Politécnica de Valencia.

Vanrell, C. R. (2007). Creación artística en la adolescencia: vinculaciones terapéuticas/ Artistic creation in adolescence: therapeutic entailments. Arteterapia, 2, 247-260. 
Manuel Pérez-Valero Artista plástico y visual. Doctor en Bellas Artes y profesor de Educación Artística en la Universidad de Granada. Director Artístico-Creativo de Enhorabuena (@enhorabuenaart), donde intenta devolver a la actividad creativa y a la educación esos factores tan importantes como son la intensificación de la sensibilidad y la agitación social.

mpvalero@ugr.es.

Ángeles Gómez-Martin llustradora, diseñadora de Moda y diseñadora Gráfica. Profesora del Grado de Diseño Gráfico en la Escuela Superior de Arte y Diseño de Andalucía, en Granada. Cursó el Máster de profesorado en Educación Secundaria Obligatoria y Bachillerato, formación Profesional y Enseñanzas de Idiomas en la Universidad de Almería.

angelagomez@esada.es 